Harvard Kennedy School Misinformation Review ${ }^{1}$

August 2021, Volume 2, Issue 4

Creative Commons Attribution 4.0 International (CC BY 4.0)

Reprints and permissions: misinforeview@hks.harvard.edu

DOI: https://doi.org/10.37016/mr-2020-75

Website: misinforeview.hks.harvard.edu

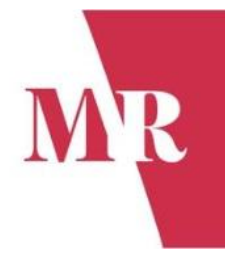

\title{
Happiness and surprise are associated with worse truth discernment of COVID-19 headlines among social media users in Nigeria
}

Do emotions we experience after reading headlines help us discern true from false information or cloud our judgement? Understanding whether emotions are associated with distinguishing truth from fiction and sharing information has implications for interventions designed to curb the spread of misinformation. Among 1,341 Facebook users in Nigeria, we find that emotions-specifically happiness and surprise-are associated with greater belief in and sharing of false, relative to true, COVID-19 headlines. Respondents who are older are more reflective, and do not support the ruling party are better at discerning true from false COVID-19 information.

Authors: Leah R. Rosenzweig (1), Bence Bago (2), Adam J. Berinsky (3), David G. Rand (4)

Affiliations: (1) Graduate School of Business, Stanford University, USA, (2) Artificial and Natural Intelligence Toulouse

Institute, France, (3) Department of Political Science, Massachusetts Institute of Technology, USA, (4) Sloan School of

Management, Massachusetts Institute of Technology, USA

How to cite: Rosenzweig, L. R., Bago, B., Berinsky A. J., \& Rand, D. G. (2021). Happiness and surprise are associated with worse truth discernment of COVID-19 headlines among social media users in Nigeria. Harvard Kennedy School (HKS) Misinformation Review, 2(4).

Received: April 14 $4^{\text {th }}, 2021$. Accepted: June 30 ${ }^{\text {th }}$ 2021. Published: August 10 2021.

\section{Research questions}

- Are emotions experienced by respondents correlated with their belief in, reading, and sharing of COVID-19 misinformation?

- Are specific emotions differentially associated with discernment of COVID-19 headlines?

- What kinds of social media users in Nigeria are better at discerning true from false information?

\section{Essay summary}

- Using a survey of 1,341 Facebook users in Nigeria, we assess whether emotional reactions are associated with belief in COVID-19 headlines, information seeking, and sharing intentions. After viewing true and false COVID-19-related headlines, respondents reported what emotions, if any, they experienced. We assess how emotions correlate with our three outcomes of interest: i) belief about the accuracy of the headline, ii) interest in clicking to read, and iii) sharing intentions.

\footnotetext{
${ }^{1}$ A publication of the Shorenstein Center on Media, Politics and Public Policy at Harvard University, John F. Kennedy School of Government.
} 
- Respondents are more likely to believe, want to read and share headlines (regardless of veracity) when they feel any emotion. Emotional responses are associated with worse truth discernment and the ability to distinguish true from false headlines when assessing belief (but not reading or sharing). We find that happiness and surprise, in particular, are associated with believing and sharing false, relative to true, headlines.

- Interventions to improve discernment of COVID-19 information should target youth, those who rely on intuition, and ruling party supporters in Nigeria.

- Understanding the role emotions play in reactions to misinformation has implications for technology platforms, governments, and citizens interested in combating the COVID-19 "infodemic." Future research should test the causal relationship between emotions and belief in COVID-19 misinformation and interventions designed to regulate specific emotions in diverse settings.

\section{Implications}

In the context of global uncertainty and anxiety about the COVID-19 pandemic, emotions may play a central role in responses to both true and false COVID-19-related headlines. This project asks whether emotions in general (and which distinct emotions) are associated with belief in, and intentions to read and share, COVID-19 misinformation. We test whether respondents in Nigeria have emotional reactions to false and true COVID-19 news headlines and examine whether an emotional response predicts greater belief in and intentions to read and share false, relative to true, headlines.

Examining these questions in Nigeria, Africa's most populous country and that with the largest number of Facebook users on the sub-continent, ${ }^{2}$ contributes to the understanding of global reactions to misinformation since existing research largely focuses on the U.S. and Europe. Critically, our data demonstrate that there is considerable need to improve social media users' ability to discern true from false pandemic information. Even though our sample is highly educated $-76 \%$ of our respondents had some university education-most respondents could not recognize false information. Specifically, $70 \%$ of respondents believed the majority of the false headlines they saw were true (see Figure A2 in Appendix A). This is a concerning statistic if the first step in curbing the spread of misinformation is correctly identifying false headlines from true headlines. However, several studies find little correlation between discernment - the ability to distinguish false from true information - and sharing of information (Guess et al., 2020; Pennycook et al., 2020; Pennycook et al., 2021). Among our respondents, even when they believed a story to be false, a minority were still interested in sharing it. Overall, $87 \%$ of respondents wanted to share at least one false news headline. Interventions designed to target both belief and sharing are necessary, especially during the pandemic as the spread of false COVID-19 "cures" can have devastating consequences. ${ }^{3}$

The main goal of this study is to assess whether emotions are associated with belief in and intentions to read and share online (mis)information. We find that experiencing any emotional reaction is associated with worse truth discernment-i.e., greater belief in the accuracy of false, relative to true, headlines. We also find that experiencing emotions is associated with greater belief and interest in clicking to read and share headlines overall (equally for true and false headlines).

We also examine correlations between particular emotions and reactions to misinformation, which complements existing studies that examine the relationship between specific emotions and information consumption. Other studies find that distinct emotions are differentially associated with deliberation

\footnotetext{
${ }^{2}$ See https://www.internetworldstats.com/stats1.htm

${ }^{3}$ See https://www.cnn.com/2020/03/23/africa/chloroquine-trump-nigeria-intl/index.html
} 
(Forgas, 2013; Holland et al., 2012; Lerner \& Tiedens, 2006), which has been shown to affect discernment (Bago et al., 2020). Anxiety has been found to increase information seeking (Valentino et al., 2008). Anger has been shown to increase susceptibility to misinformation (Greenstein \& Franklin, 2020; Han et al., 2020). Counter to these studies, we do not find robust results for anger and fear. Instead, we find that happiness and surprise are associated with worse discernment and greater sharing of false, relative to true, headlines. This departure from existing work could be due to differing samples, since most of the empirical literature comes from WEIRD populations, ${ }^{4}$ and/or the fact that our study specifically focuses on COVID-19 information.

Our findings have implications for policymakers, social media platforms, academics, and practitioners engaged in online digital literacy and campaigns to fight the spread of misinformation. We might expect emotions to predict belief and sharing behavior during public health crises, when emotions may be particularly intense. Yet there is a dearth of empirical evidence in this area, particularly from the Global South. Studies on the correspondence between emotions and discernment generally rely on U.S.-based samples (Martel et al., 2020). Given that fact-checking sites often advocate for regulating or suppressing emotions as a way to combat misinformation, the aim of our study is to understand the role emotions play in reactions to misinformation.

Our findings demonstrate that emotions are related to belief, clicking, and sharing of COVID-19related information among social media users in Nigeria, and lend insights into containment and mitigation strategies in an important non-Western context. Future research should test interventions designed to regulate happiness and surprise, which may cloud one's judgement and inhibit discernment. For instance, asking whether a headline evokes a particular emotion-such as happiness or surprise-may help individuals recognize these specific emotions. Light touch interventions that get users to identify their current emotional states might also help regulate particular emotions (Gross, 2002). Similarly, a prompt like "Just because a story makes you happy does not mean it's true" could serve as a nudge to consider the accuracy of the headline (Pennycook et al., 2021). Furthermore, social media companies could use this information on the emotional reactions users have to posts (offered by their emoji reactions) to identify which posts might be more emotionally evocative, potentially more harmful, and then preferentially target these posts for fact-checking, flagging, and other mitigation strategies.

Given that respondent samples from Facebook in the Global South tend to be more urban and educated than average citizens (Rosenzweig et al., 2020), which may also reflect differential patterns of social media use in these contexts, it will be important to ensure that interventions are designed with these users in mind. In contexts where access to the internet and social media may be more recent, digital literacy trainings, which have been proven effective in other non-Western contexts may be important (Guess et al., 2020; Badrinathan, 2020). Such trainings could include techniques to spot emotionally evocative posts and could target social media users most susceptible to falling for misinformation.

Finally, these findings have implications for tackling the ongoing infodemic and pandemic, by providing insights into which users are most vulnerable to misinformation. Our results demonstrate how social media users in Nigeria vary in terms of their susceptibility to false news, and where interventions should be focused-specifically on users who rely on intuition, younger users, and those who support the governing party. Similar to other studies with U.S. subjects, we find that cognitive reflection, measured by Cognitive Reflective Test (CRT), is positively associated with discernment (Pennycook \& Rand, 2019). While identifying low-CRT individuals may be practically challenging, our results suggest that interventions could target younger social media users and ruling party supporters who are worse at discerning true from false

\footnotetext{
${ }^{4}$ WEIRD stands for Western, Educated, Industrialized, Rich, and Democratic (Henrich et al., 2010).
} 
COVID-19 information. ${ }^{5}$ Further research is required to understand whether the negative relationship we observe between governing party support and discernment persists even when another party controls the Presidency in Nigeria. Our findings suggest that partisanship is an important variable to pay attention to in the study of susceptibility to online misinformation, even in a context where party identification is relatively weak compared to the U.S. Further research is required to understand what kinds of interventions might help governing party supporters become better at truth discernment, and whether these would or would not have backlash effects among non-partisans and opposition supporters.

Given the existing cross-national evidence that susceptibility to COVID-19 misinformation is negatively associated with self-reported willingness to get vaccinated against the virus (Roozenbeek et al., 2020), these users might serve as the focal point for interventions targeting misinformation about the COVID-19 vaccine.

\section{Findings}

Finding 1: Emotionally evocative headlines are more likely to be believed, clicked, and shared.

When respondents have an emotional reaction to a headline, they are more likely to believe, want to read, and share that headline, regardless of whether it is true or false. Feeling any emotion is positively associated with our three outcomes of interest for all headlines (see Figure 1). Are emotions differentially associated with these outcomes based on the veracity of the headline? Meaning, are respondents more likely to believe, click, and share false relative to true headlines when they feel emotions overall and when they feel specific emotions?

In the study of misinformation, we not only care about the correlates of belief but also the correlates of discernment-i.e., the ability to distinguish true from false information. Here we find that emotional reactions are associated with worse truth discernment. Experiencing any emotion after reading a headline is associated with greater belief in false headlines relative to true headlines. Our respondents were better at discerning true from false news when they experienced no emotion after reading a headline. ${ }^{6}$ We find no statistically significant differential relationship between emotion and clicking to read or sharing false headlines over true headlines. In other words, we cannot be sure that the differences we observe for reading and sharing outcomes are not simply due to chance.

\footnotetext{
${ }^{5}$ Age and political affiliation may be easier to identify since users have to report their age to Facebook, and many often follow political pages or join political groups. For instance, one "APC Nigeria” Facebook group has 40k members.

${ }^{6}$ This result is robust to the inclusion of control variables in our models, including age, gender, education, social media use, and support for the governing party (APC) (see Table C3 in Appendix C).
} 

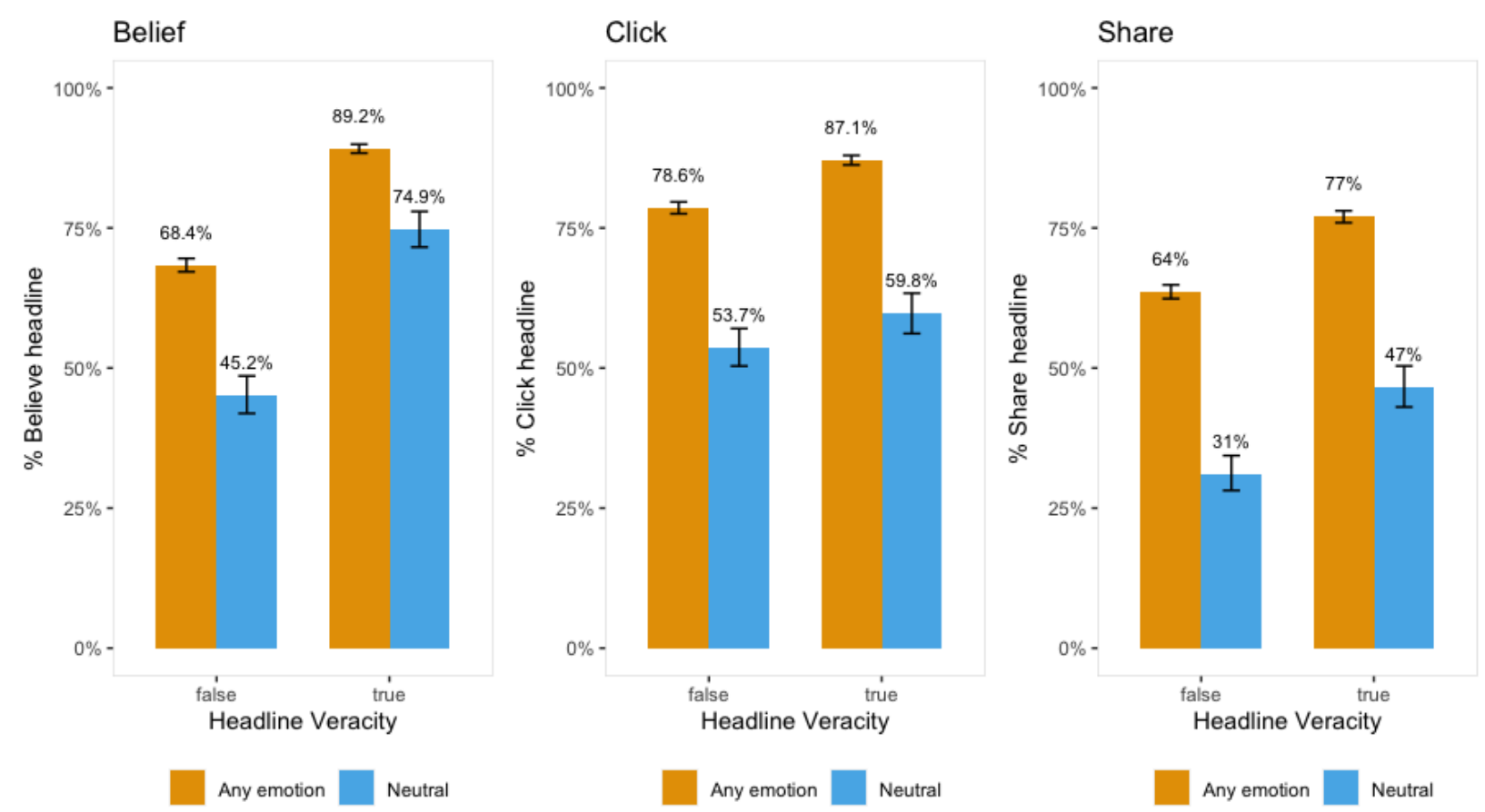

Figure 1. Rate of belief in, clicking, and sharing of headlines by true/false headline veracity and respondents' emotional reaction. Blue bars indicate headlines where respondents reported feeling no emotion at all (neutral). Orange bars indicate headlines where respondents reported feeling any of the six distinct emotions presented (anger, fear, sadness, happiness, surprise, and disgust). Error bars represent 95\% confidence intervals.

Finding 2: Happiness and surprise are associated with worse discernment of headlines.

Examining each of the six distinct emotions, we find that half of these emotions are associated with increased belief, clicking to read, and sharing of any headline. Fear, happiness, and surprise are positively associated with our three outcomes overall, for both true and false headlines. Sadness is also positively correlated with overall outcomes, but this relationship is not statistically significant. Anger and disgust are negatively associated with overall belief in, clicking, and sharing of headlines. This last result may indicate that people use an "affect heuristic" when evaluating headlines and are less likely to believe a headline, regardless of its veracity, if their affective evaluation of the headline is negative-e.g., when they feel negative emotions, such as anger or disgust (Slovic et al., 2007).

Analyzing each distinct emotion's correspondence with discernment, we find that happiness and surprise are both negatively and significantly associated with truth discernment. While happiness is associated with increased belief in both true and false headlines, this relationship is stronger for false than true (see left panel in Figure 2). Surprise, on the other hand, is associated with both increased belief in false headlines and reduced belief in true headlines. Similarly, happiness and surprise are also associated with greater likelihood of wanting to share false headlines, compared to true headlines. ${ }^{7}$ We do not find a robust relationship between these emotions, headline veracity, and clicking to read the story. The other four emotions we measured all have a positive correlation with discernment, as well as clicking and sharing more true, relative to false, headlines, but none of these relationships are statistically significant. ${ }^{8}$

\footnotetext{
${ }^{7}$ These results are consistent also when we include controls for age, gender, education, social media use, and APC support in our model (see Tables C4 and C5 in Appendix C). Section C.3 in Appendix C interacts APC support with our independent variables of interest (emotion and headline veracity) and finds consistent results.

${ }^{8}$ All regression tables are provided in Appendix B.
} 

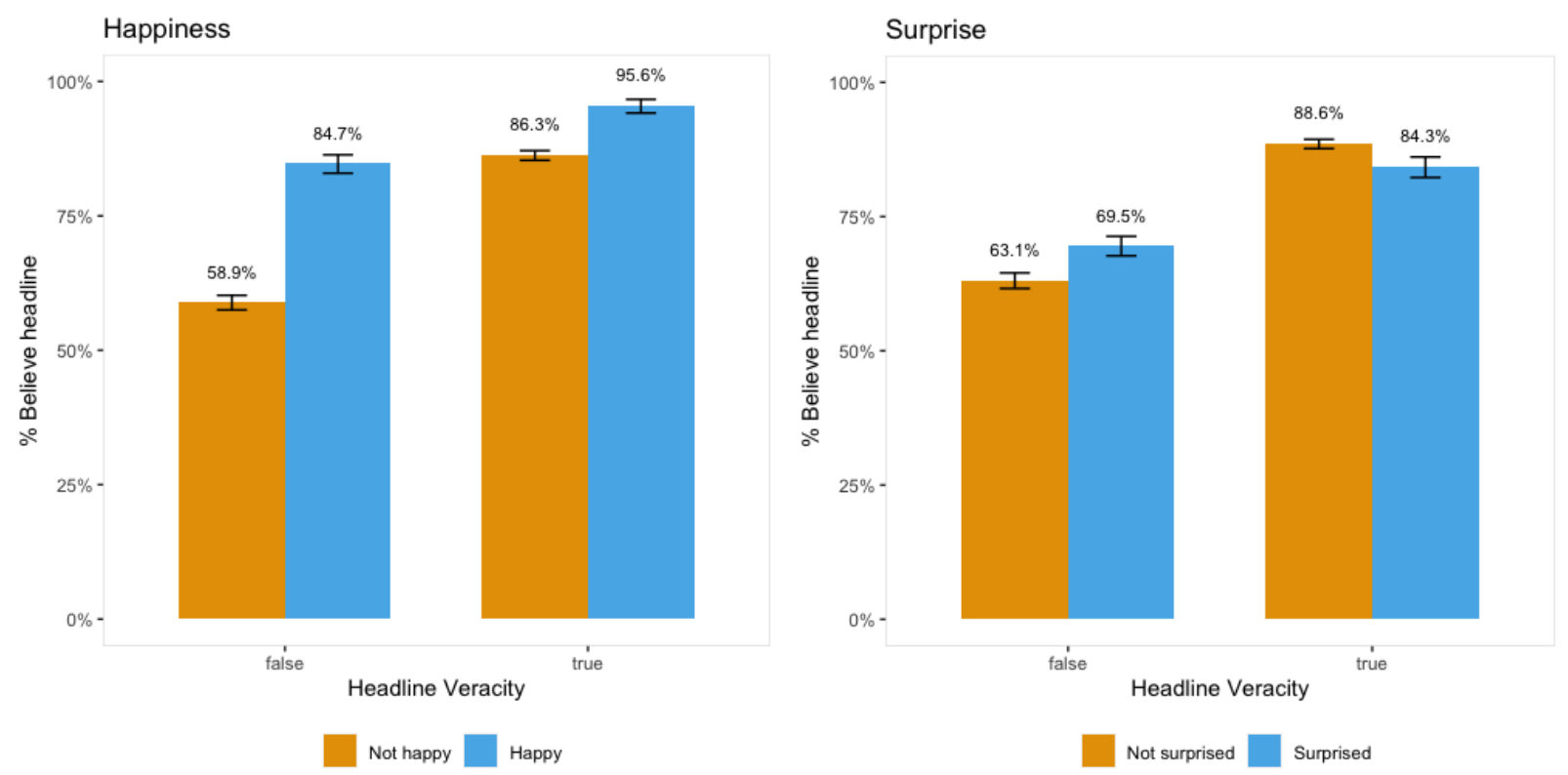

Figure 2. Rate of belief in true/false headlines for happiness and surprise. Blue bars indicate headlines where respondents reported feeling that particular emotion. Orange bars indicate headlines where respondents reported not feeling that particular emotion. Error bars represent $95 \%$ confidence intervals.

Finding 3: Older respondents, more reflective respondents, and respondents who do not support the governing party are better at discerning true from false COVID-19 information.

As displayed in Figure 3, we find that particular characteristics are significantly correlated with discernment of COVID-19 information among our sample of Nigerian Facebook users. Again, by discernment we mean the ability to distinguish true from false headlines, as evidenced by respondents saying they believe the true headlines are accurate and the false ones are not. We give each respondent a discernment score, which is the number of headlines they correctly identified as true or false (out of the 10 they saw) and use this as our outcome variable to see what respondent-level characteristics predict better discernment.

We find that reflecting or deliberating, rather than relying on intuition when making decisions, as measured by the Cognitive Reflection Test is significantly associated with truth discernment, as is being older and living in a mostly urban area (Frederick, 2005)..$^{9}$ The positive correlation we observe between age and discernment is consistent with evidence from survey experiments with U.S. samples (Pennycook et al., 2021), but counter to the analysis of social media data among U.S. users (Grinberg et al., 2019). The positive association we observe between CRT scores and discernment is also consistent with existing research (Pennycook \& Rand, 2019).

\footnotetext{
${ }^{9}$ All of the demographic, social media use, cognitive reflection, and political variables we use to predict this discernment score were measured in our survey after the main task of presenting headlines, measuring emotional reactions, and our three outcome measures. The coefficient on urban has a p-value $=.055$.
} 


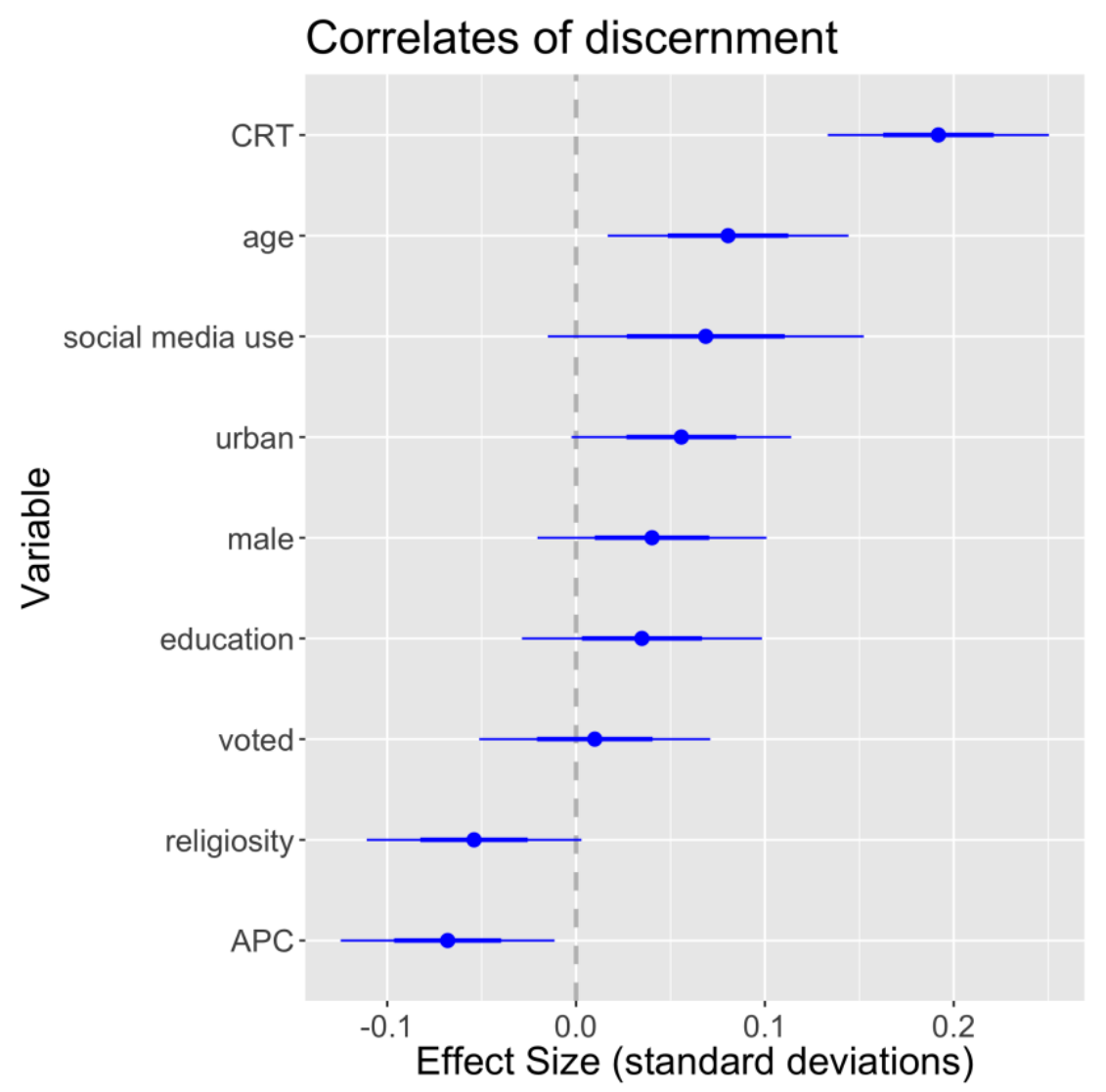

Figure 3. Coefficients predicting discernment (the number out of 10 headlines each respondent correctly identified as true or false). All variables have been standardized, mean-centered and scaled by standard deviation for comparability. Thin lines indicate 95\% confidence intervals (Cls), thick lines indicate 90\% Cls. Right of the dotted zero line (i.e., positive values) indicates a positive correlation with discernment and decreased susceptibility to misinformation.

We also observe important negative correlations with discernment. First, we find that supporting the All Progressives Congress (APC), the current ruling party in Nigeria, is negatively correlated with discernment. We measured partisanship by first asking "do you feel close to any political party?" The 23\% of respondents who answered "yes" were then asked, "Which party is that?" Options included All Progressive Congress (APC)-47\%, Peoples' Democratic Party (PDP)-48\% and other-5\%. ${ }^{10}$ Second, religiosity is negatively correlated with discernment ( $p$-value $=.058)$. For partisanship, this correlation could be driven by greater trust in the media among ruling party supporters in Nigeria. More religious people, who might be more likely to hold views that God will protect believers from COVID-19, might exert less effort in truth discernment with respect to COVID-19 information because they feel protected. ${ }^{11}$ Other studies similarly observe a negative association between religiosity and discernment (Bronstein et al., 2019). Further research is required to understand the mechanism for these correlations.

\footnotetext{
${ }^{10}$ The percent of respondents who do not feel close to any party may seem low, but it is not uncommon in Nigeria. Here partisan affiliation tends to be weaker than say the U.S. - as is evident by the fact that about half (51\%) of respondents in the most recent nationally representative Afrobarometer survey said they do not feel close to any political party (Afrobarometer, 2018). Although partisanship is less entrenched in Nigeria, despite being a competitive democracy with two major parties like the U.S., it does not invalidate our finding that APC partisans are worse at discerning true from false headlines than other respondents.

${ }^{11}$ Findings from a nationally representative phone survey released by NOI Polls in March 2020 revealed that $26 \%$ of Nigerians believed they are immune from COVID-19, and $40 \%$ of those people said it was because they are a "child of God." (Source: https://noi-polls.com/covid-19-poll-result-release/)
} 
Finally, we find that gender, education, social media use, and voting behavior are not statistically significant predictors of discernment. Recognizing that information about health crises may be particularly emotional, and quite distinct from general online misinformation, the results from this study should not be generalized to other types of misinformation.

\section{Methods}

From April 1st to April 3rd, 2020, we conducted an online study of 1,341 Facebook users in Nigeria to understand the relationship between emotional reactions and belief in, reading intentions and sharing intentions of COVID-19-related misinformation. We had three research questions of interest. First, we investigated the relationship between emotions and our outcomes. Specifically, we wanted to know if emotional reactions to headlines were associated with greater belief in, reading, and sharing of false stories (compared to true stories). We selected these outcome measures following existing research on misinformation (Bode \& Vraga, 2018; Guess et al., 2019; Pennycook et al., 2020; Tully et al.,2019), and also because they follow the logical process of reacting to a headline-first thinking about whether it is true, deciding whether to click to read it, and then sharing. Second, we examined these relationships for distinct emotions. Finally, we observed the individual characteristics that are associated with the ability to discern true from false headlines.

This research was designed to test the generally assumed but seldom tested claim that emotionally evocative headlines are harder to decipher as true or false. Media outlets have suggested that people fall for spreading misinformation because it is emotionally evocative (Barr, 2019; Lunch, 2019). From psychology research, which suggests that deliberation improves discernment (Bago et al., 2020; Pennycook \& Rand, 2019), we might also expect emotions to inhibit deliberation and therefore be associated with worse discernment. Drawing on these ideas, we prespecified two main hypotheses for this research. ${ }^{12}$

- H1: Respondents will be more likely to believe false headlines when they experience an emotional response.

- $\quad H 2$ : Respondents will be more likely to want to click to read and share false headlines when they have an emotional response.

Using Facebook advertisements, we recruited a sample of social media users in Nigeria aged 18 years old and older. Our sample is $68 \%$ male, $32 \%$ female, $76 \%$ have some university education, with the mean age of respondents being 28 years old. Though quite different from average citizens in Nigeria, this group of social media users - who clicked on an ad to take a survey-is a population of particular interest given the prevalence of misinformation on social media (Allcott et al., 2019; Wang et al., 2019). We focus on Nigeria because it is the most populous country in Africa, a media hub on the continent, and a prominent source of both fact-checking resources and an origin of COVID-19-related misinformation. ${ }^{13}$

Facebook users who clicked on our ads were taken to a Qualtrics survey and shown media posts about COVID-19 that had appeared online. Respondents were asked a series of questions about these posts and then answered demographic questions, took the Cognitive Reflection Test (CRT), ${ }^{14}$ and reported their social media use. Respondents who completed the survey and provided their phone number were given $\sim 1.50$ USD in airtime sent to their mobile phone for their participation.

\footnotetext{
${ }^{12}$ Our preanalysis plan is available on OSF (https://osf.io/vypfn/).

${ }^{13}$ See https://www.poynter.org/coronavirusfactsalliance/

${ }^{14}$ This test is commonly used in psychology as a tool to measure an individual's predisposition towards intuitive or "gut" reactions versus more reflective or deliberate decision making (Frederick, 2005).
} 
We obtained the true media posts ("stimuli") from major news outlets in Nigeria, including The Guardian, Daily Post, and Premium Times. The false stimuli came from COVID-19 stories that had appeared online but had subsequently been fact-checked (and verified as untrue) by AfricaCheck.org. All stimuli actually appeared online in Nigeria prior to the experiment. Each respondent saw 10 total COVID-19related headlines, five true and five false, the order of which was random. ${ }^{15}$ Headlines were a mix of stories about the state of the pandemic, travel, potential cures, and actions of and statements by political leaders. ${ }^{16}$

After viewing each headline, respondents were asked to select any number of six emojis, each representing a distinct basic emotion (Ekman, 1992), to indicate how the headline made them feel (see Figure 4). Before the survey, we conducted a pretest with a separate sample of 76 Nigerians to confirm that the emojis were interpreted correctly. A majority of respondents were able to identify the emotion associated with each emoji. ${ }^{17}$ In the main survey, respondents indicated they felt surprise, fear, anger, disgust, happiness, sadness, or any combination of these emotions using these emojis (see Figure 4). The order of the emotions was randomized for each respondent. Respondents also had the option to report that they felt "neutral/no emotion." If they felt any emotion after reading the headline, respondents were asked a follow-up question: "On a scale from 1 (not very strongly) to 7 (very strongly), how strongly did you feel [emotion]?"18

\section{Please select the emoji(s) that best represent your emotional state when you read the headline. (Remember you can select more than 1):}
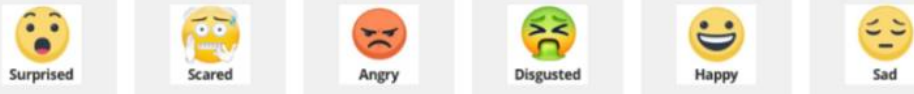

Neutral/

No emotion

Figure 4. Survey question measuring emotional response with emoji response options.

Since relying on self-reported emotional states requires respondents to accurately understand and report their emotional reactions (Settle 2018), we would have ideally used an automatic or biological measure of emotions immediately after respondents read the headline. Because this was impossible in the context of an online survey, participants were randomly assigned to either give a response to the belief question or the emotion measure first after seeing the headline. We do this because studies show that labeling emotions can act as emotion regulation (Torre \& Lieberman, 2018), reducing felt emotions. Asking about emotions after belief, however, is post-treatment with respect to this outcome. We observed no ordering effects in terms of the relationship between reported emotions and belief, and therefore pool data across these two conditions when analyzing the data (see Appendix C).

Belief was measured using the following question: "Do you think this headline accurately describes an event that actually happened?" We also asked whether respondents were (hypothetically) interested

\footnotetext{
15 The 10 stimuli are presented in Appendix D.

16 We included a mix of political and non-political headlines to reflect the range of the types of headlines respondents would naturally be exposed to on social media concerning the pandemic, based on our own experience following media outlets in Nigeria on Twitter and Facebook at this time. At the end of the survey, respondents were informed which headlines were false and which were true.

${ }^{17}$ Accuracy ranged from $55 \%$ for the "scared" emoji to $100 \%$ for "happy."

18 The results from this measure of emotional strength are consistent with the main results presented here and are provided in Appendix C.
} 
in clicking to read the headline and sharing the headline online. All responses were binary-respondents could either answer "yes" or "no."

To analyze the correlation between emotional reactions and our outcomes of interest we use linear mixed-effects models. ${ }^{19}$ These models account for the interdependence between observations because outcomes for the same respondent and for the same headline rated by each respondent are likely correlated. We include random effects for respondents and headlines because we are not interested in the specific influence of the particular individual or headline on the outcomes, rather we want to know whether emotions are correlated with the outcomes while controlling for the variation coming from specific headlines and respondents. We run a separate regression for each distinct emotion and interact the emotion dummy with the headline veracity indicator.

Finally, we observe which types of respondents are more likely to believe false, rather than true, COVID-19 information, and assess the correlates of truth discernment among our sample. We use a linear regression to examine whether several demographic variables, as well as CRT scores, self-reported social media use, partisanship, religiosity, and past voting behavior predict discernment-the proportion of the 10 total headlines the respondent correctly identified as true or false (see Figure 3 ). In line with our preregistered secondary hypothesis, we find that more reflective users, as measured by the Cognitive Reflection Test (CRT) are better at discerning true from false headlines.

\section{Bibliography}

Afrobarometer Data, Nigeria, round 7. (2018). Afrobarometer. http://www.afrobarometer.org

Allcott, H., Gentzkow, M., \& Yu, C. (2019). Trends in the diffusion of misinformation on social media. Research \& Politics, 6(2), 1-8. https://doi.org/10.1177/2053168019848554

Badrinathan, S. (2021). Educative interventions to combat misinformation: Evidence from a field experiment in India. American Political Science Review, 1-17. https://doi.org/10.1017/S0003055421000459

Bago, B., Rand, D. G., \& Pennycook, G. (2020). Fake news, fast and slow: Deliberation reduces belief in false (but not true) news headlines. Journal of Experimental Psychology: General, 149(8), 16081613. https://doi.org/10.1037/xge0000729

Barr, R. A. (2019). Fake news grabs our attention, produces false memories and appeals to our emotions. The Conversation. https://theconversation.com/fake-news-grabs-our-attention-produces-falsememories-and-appeals-to-our-emotions-124842

Bode, L., \& Vraga, E. K. (2018). See something, say something: Correction of global health misinformation on social media. Health Communication, 33(9), 1131-1140. https://doi.org/10.1080/10410236.2017.1331312

Brauer, M. \& Curtin, J. J. (2018). Linear mixed-effects models and the analysis of nonindependent data: A unified framework to analyze categorical and continuous independent variables that vary within subjects and/or within-items. Psychological Methods, 23(3), 1-23. https://doi.org/10.1037/met0000159

Bronstein, M. V., Pennycook, G., Bear, A., Rand, D. G., \& Cannon, T. D. (2019). Belief in fake news is associated with delusionality, dogmatism, religious fundamentalism, and reduced analytic thinking. Journal of Applied Research in Memory and Cognition, 8(1), 108-117. https://doi.org/10.1016/j.jarmac.2018.09.005

\footnotetext{
${ }^{19}$ Details of the model and tables presenting analyses for each emotion and all three outcomes are presented in Appendix B.
} 
Ekman, P. (1992). An argument for basic emotions. Cognition \& Emotion, 6(3-4), 169-200. https://doi.org/10.1080/02699939208411068

Forgas, J. P. (2013). Don't worry, be sad! On the cognitive, motivational, and interpersonal benefits of negative mood. Current Directions in Psychological Science, 22(3), 225-232. https://doi.org/10.1177/0963721412474458

Frederick, S. (2005). Cognitive reflection and decision making. The Journal of Economic Perspectives, 19(4), 25-42. https://doi.org/10.1257/089533005775196732

Greenstein, M., \& Franklin, N. (2020). Anger increases susceptibility to misinformation. Experimental Psychology, 67(3), 202-209. https://doi.org/10.1027/1618-3169/a000489

Grinberg, N., Joseph, K., Friedland, L., Swire-Thompson, B., \& Lazer, D. (2019). Fake news on Twitter during the 2016 U.S. presidential election. Science, 363(6425), 374-378. https://doi.org/10.1126/science.aau2706

Gross, J. J. (2002). Emotion regulation: Affective, cognitive, and social consequences. Psychophysiology, 39(3), 281-291. https://doi.org/10.1017/S0048577201393198

Guess, A. M., Lerner, M., Lyons, B., Montgomery, J. M., Nyhan, B., Reifler, J., \& Sircar, N. (2020). A digital media literacy intervention increases discernment between mainstream and false news in the United States and India. Proceedings of the National Academy of Sciences, 117(27), 1553615545. https://doi.org/10.1073/pnas.1920498117

Guess, A., Nagler, J., \& Tucker, J. (2019). Less than you think: Prevalence and predictors of fake news dissemination on Facebook. Science Advances, 5(1), 1-8. https://doi.org/10.1126/sciadv.aau4586

Han, J., Cha, M., \& Lee, W. (2020). Anger contributes to the spread of COVID-19 misinformation. Harvard Kennedy School (HKS) Misinformation Review, 1(3), 1-14. https://doi.org/10.37016/mr-2020-39

Henrich, J., Heine, S., \& Norenzayan, A. (2010). The weirdest people in the world? Behavioral and Brain Sciences, 33(2-3), 61-83. https://doi.org/10.1017/S0140525X0999152X

Holland, R. W., de Vries, M., Hermsen, B., \& van Knippenberg, A. (2012). Mood and the attitudebehavior link: The happy act on impulse, the sad think twice. Social Psychological and Personality Science, 3(3), 356-364. https://doi.org/10.1177/1948550611421635

Lerner, J. S., \& Tiedens, L. Z. (2006). Portrait of the angry decision maker: How appraisal tendencies shape anger's influence on cognition. Journal of Behavioral Decision Making, 19, 115-137. https://doi.org/10.1002/bdm.515

Lynch, M. P. (2019). Do we really understand "fake news"? The New York Times. https://www.nytimes.com/2019/09/23/opinion/fake-news.html

Martel, C., Pennycook, G., \& Rand, D. (2020). Reliance on emotion promotes belief in fake news. Cognitive Research: Principles and Implications, 5(47), 1-20. https://doi.org/10.1186/s41235$\underline{020-00252-3}$

Pennycook, G., Epstein, Z., Mosleh, M., Arechar, A. A., Eckles, D., \& Rand, D. G. (2021). Shifting attention to accuracy can reduce misinformation online. Nature, 592, 590-595. https://doi.org/10.1038/s41586-021-03344-2

Pennycook, G., Bear, A., Collins, E. T., \& Rand, D. G. (2020). The implied truth effect: Attaching warnings to a subset of fake news headlines increases perceived accuracy of headlines without warnings. Management Science, 66(11), 4944-4957. https://doi.org/10.1287/mnsc.2019.3478

Pennycook, G., McPhetres, J., Zhang, Y., Lu, J., \& Rand, D. G. (2020). Fighting COVID-19 misinformation on social media: Experimental evidence for a scalable accuracy nudge intervention. Psychological Science, 31(7), 770-780. https://doi.org/10.1177/0956797620939054

Pennycook, G., \& Rand, D. G. (2019). Lazy, not biased: Susceptibility to partisan fake news is better explained by lack of reasoning than by motivated reasoning. Cognition, 188, 39-50. https://doi.org/10.1016/i.cognition.2018.06.011 
Roozenbeek, J., Schneider, C. R., Dryhurst, S., Kerr, J., Freeman, A. L., Recchia, G., van der Bles, A. M., \& van der Linden, S. (2020). Susceptibility to misinformation about COVID-19 around the world. Royal Society Open Science, 7, 1-15. https://doi.org/10.1098/rsos.201199

Rosenzweig, L. R., Bergquist, P., Hoffmann Pham, K., Rampazzo, F., \& Mildenberger, M. (2020). Survey sampling in the Global South using Facebook advertisements. SocArXiv. https://doi.org/10.31235/osf.io/dka8f

Settle, J. E. (2018). Moving beyond sentiment analysis. In B. Foucault Welles \& S. González-Bailón (Eds.) The Oxford Handbook of Networked Communication (pp. 349-377). Oxford University Press. https://doi.org/10.1093/oxfordhb/9780190460518.013.20

Slovic, P., Finucane, M. L., Peters, E., \& MacGregor, D. G. (2007). The affect heuristic. European Journal of Operational Research, 177(3), 1333-1352. https://doi.org/10.1016/j.ejor.2005.04.006

Torre, J. B., \& Lieberman, M. D. (2018). Putting feelings into words: Affect labeling as implicit emotion regulation. Emotion Review, 10(2), 116-124. https://doi.org/10.1177/1754073917742706

Tully, M., Vraga, E. K., \& Bode, L. (2020). Designing and testing news literacy messages for social media. Mass Communication and Society, 23(1), 22-46. https://doi.org/10.1080/15205436.2019.1604970

Valentino, N. A., Hutchings, V. L., Banks, A. J., \& Davis, A. K. (2008). Is a worried citizen a good citizen? Emotions, political information seeking, and learning via the internet. Political Psychology, 29(2), 247-273. https://doi.org/10.1111/j.1467-9221.2008.00625.x

Wang, Y., McKee, M., Torbica, A., \& Stuckler, D. (2019). Systematic literature review on the spread of health-related misinformation on social media. Social Science \& Medicine, 240, 1-12. https://doi.org/10.1016/i.socscimed.2019.112552 


\section{Funding}

This research was funded by the Institute for Advanced Study in Toulouse (IAST) Multidisciplinary Prize 2019. Bago was supported by ANR grant ANR-17-EURE-0010 (Investissements d'Avenir program), and ANR Labex IAST. Rand acknowledges support from the William and Flora Hewlett Foundation, the Omidyar Network, the John Templeton Foundation grant 61061.

\section{Competing interests}

Berinsky and Rand have received funding for other projects from Google. Berinsky and Rosenzweig received funding for other projects from Facebook.

\section{Ethics}

This research was deemed exempt by the MIT IRB, listed as protocol number E-2076 on March 22, 2020, and approved by the TSE-IAST Review Board for Ethical Standards in Research (protocol \#: 2020-03-003) on March 27, 2020. All respondents provided informed consent. Gender was collected in order to test whether it is an important social identity category with respect to misinformation consumption. Gender was self-reported by respondents with categories provided by the investigators (gender: male/female). Ethnicity was not deemed relevant for this study.

\section{Copyright}

This is an open access article distributed under the terms of the Creative Commons Attribution License, which permits unrestricted use, distribution, and reproduction in any medium, provided that the original author and source are properly credited.

\section{Data availability}

All materials needed to replicate this study are available via the Harvard Dataverse: https://doi.org/10.7910/DVN/1DC7PA 


\section{Appendix A: Descriptive statistics}

Table A1. Descriptive statistics of study respondents.

\begin{tabular}{lcccccccc}
\hline \hline Statistic & $\mathrm{N}$ & Mean & St. Dev. & Min & Pctl $(25)$ & Median & Pctl $(75)$ & Max \\
\hline Female & 1,325 & 0.32 & 0.47 & 0.00 & 0.00 & 0.00 & 1.00 & 1.00 \\
Age & 1,321 & 28.00 & 7.00 & 18.00 & 22.00 & 26.00 & 31.00 & 62.00 \\
Some university & 1,321 & 0.76 & 0.43 & 0.00 & 1.00 & 1.00 & 1.00 & 1.00 \\
Urban & 1,297 & 0.80 & 0.40 & 0.00 & 1.00 & 1.00 & 1.00 & 1.00 \\
Employed & 1,316 & 0.49 & 0.50 & 0.00 & 0.00 & 0.00 & 1.00 & 1.00 \\
Christian & 1,316 & 0.76 & 0.43 & 0.00 & 1.00 & 1.00 & 1.00 & 1.00 \\
Religiosity & 1,298 & 3.20 & 0.99 & 0.00 & 3.00 & 4.00 & 4.00 & 4.00 \\
Voted & 1,318 & 0.45 & 0.50 & 0.00 & 0.00 & 0.00 & 1.00 & 1.00 \\
APC supporter & 1,341 & 0.11 & 0.31 & 0 & 0 & 0 & 0 & 1 \\
Daily FB user & 1,314 & 0.74 & 0.44 & 0.00 & 0.00 & 1.00 & 1.00 & 1.00 \\
\hline
\end{tabular}

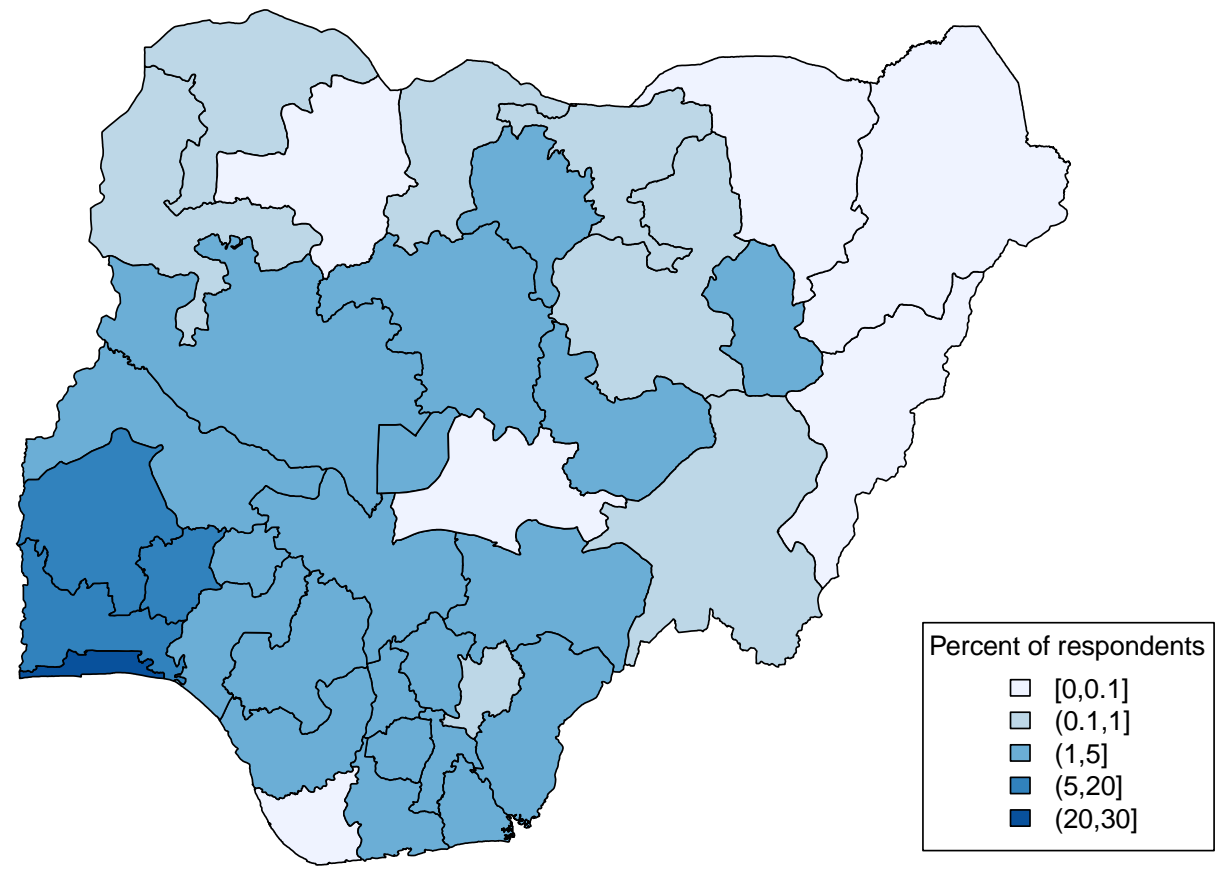

Figure A1. Percent of respondents from each state in Nigeria. 


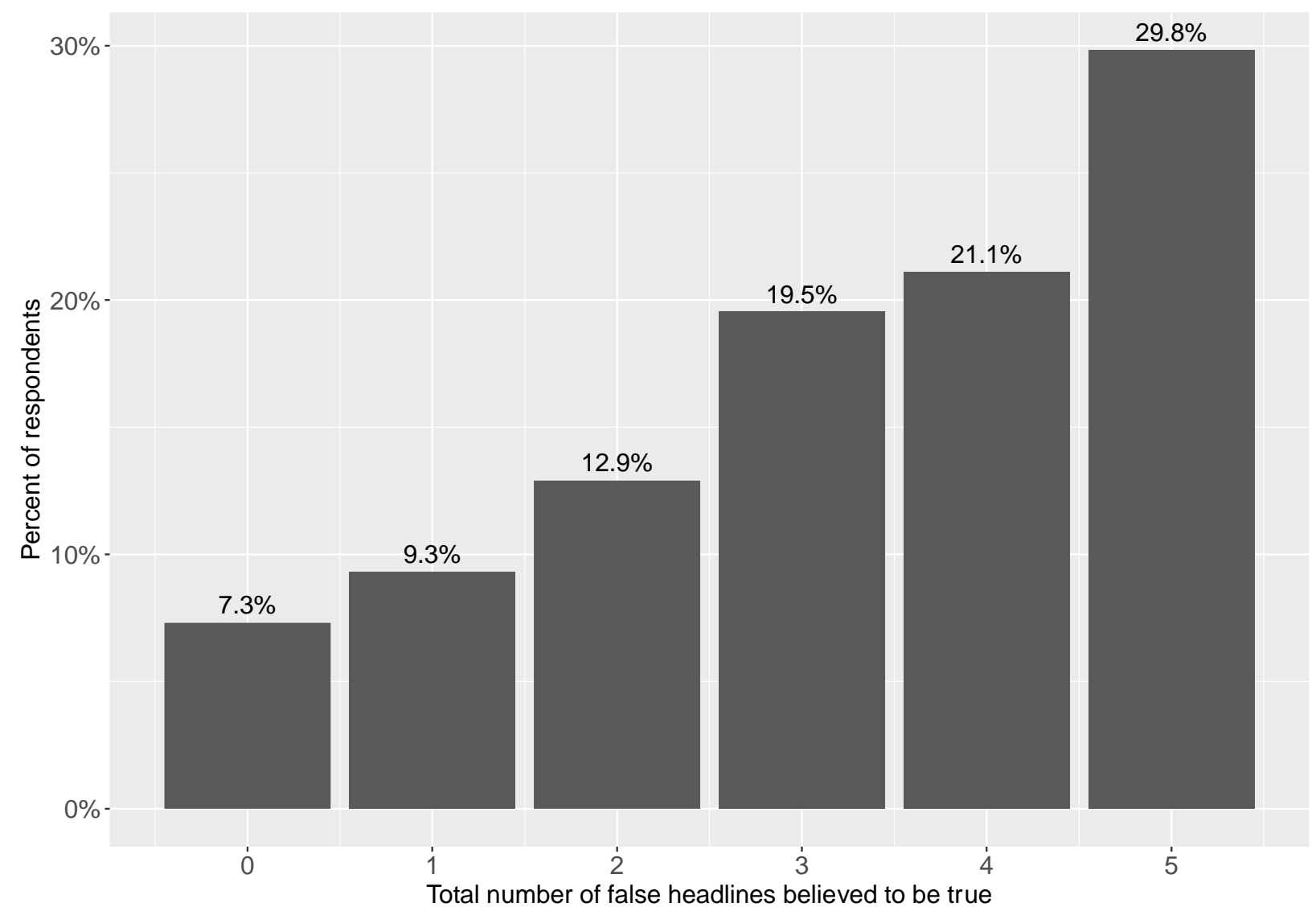

Figure A2. Percent of respondents who believed false headlines were true. 


\section{Appendix B: Main results models and tables}

\section{B.1 Mixed-effects model}

For the analysis, we use mixed-effect models with random intercepts for respondents and headlines and a random slope for headlines. ${ }^{20}$ This mixed-effects model accounts for the interdependence between observations because participants rate several headlines, and all headlines are assessed by all participants. The model we use in all of our main specifications is: ${ }^{21}$

$$
y=\beta_{0}+\beta_{1} \text { true }+\beta_{2} \text { emo }+\beta_{3} \text { true } * \text { emo }+u_{0}+v_{0}+v_{1} \text { emo }+\epsilon
$$

Here emo represents the emotion rating by respondents, which varies within headlines and between respondents, and true is the veracity of the headline (true/false), which varies within respondent and between headlines. The $\beta$ 's estimate the fixed effects, $u_{0}$ estimates the by-respondent random intercept, and $v_{0}$ and $v_{1}$ estimate the by-headline random effects (intercept and slope, respectively). We use linear regression models for all of the main analyses presented in the following tables for each of our outcomes of interest $(y)$, belief, click, and share.

Table B1. Association between neutral (no emotion) and belief, click, and share.

\begin{tabular}{lccc}
\hline \hline & \multicolumn{3}{c}{ Dependent variable: } \\
\cline { 2 - 4 } & belief & click & share \\
\hline \multirow{2}{*}{ neutral } & $-0.17^{* * *}$ & $-0.21^{* * *}$ & $-0.22^{* * *}$ \\
& $(0.03)$ & $(0.02)$ & $(0.02)$ \\
true & $0.26^{* * *}$ & 0.07 & $0.15^{*}$ \\
& $(0.09)$ & $(0.07)$ & $(0.08)$ \\
neutral:true & $0.11^{*}$ & -0.03 & 0.03 \\
& $(0.06)$ & $(0.04)$ & $(0.04)$ \\
Constant & $0.70^{* * *}$ & $0.72^{* * *}$ & $0.58^{* * *}$ \\
& $(0.05)$ & $(0.03)$ & $(0.04)$ \\
\hline Observations & 13,410 & 13,409 & 13,409 \\
\hline \hline \multirow{2}{*}{ Note: } & ${ }^{*} \mathrm{p}<0.1 ;{ }^{* *} \mathrm{p}<0.05 ;{ }^{* * *} \mathrm{p}<0.01$
\end{tabular}

\footnotetext{
${ }^{20} \mathrm{We}$ planned to include random slopes for both respondents and headlines but ran into singularity issues. As described in our preanalysis plan, we excluded a random slope from the model, following Brauer and Curtin (2018), so the models would converge.

${ }^{21}$ For the "surprise," emotion we only include random intercepts due to singularity.
} 
Table B2. Association between happy and belief, click, and share.

\begin{tabular}{lccc}
\hline \hline & \multicolumn{3}{c}{ Dependent variable: } \\
\cline { 2 - 4 } & belief & click & share \\
\hline happy & $0.16^{* * *}$ & $0.11^{* * *}$ & $0.16^{* * *}$ \\
& $(0.03)$ & $(0.02)$ & $(0.03)$ \\
true & $0.19^{* * *}$ & 0.08 & $0.11^{*}$ \\
& $(0.06)$ & $(0.05)$ & $(0.06)$ \\
happy:true & $-0.20^{* * *}$ & $-0.09^{*}$ & $-0.19^{* * *}$ \\
& $(0.06)$ & $(0.05)$ & $(0.05)$ \\
Constant & $0.80^{* * *}$ & $0.83^{* * *}$ & $0.70^{* * *}$ \\
& $(0.03)$ & $(0.02)$ & $(0.03)$ \\
\hline Observations & 13,410 & 13,409 & 13,409 \\
\hline \hline \multirow{2}{*}{ Note: } & ${ }^{*} \mathrm{p}<0.1 ;{ }^{* *} \mathrm{p}<0.05 ;{ }^{* * *} \mathrm{p}<0.01$
\end{tabular}

Table B3. Association between surprise and belief, click, and share.

\begin{tabular}{lccc}
\hline \hline & \multicolumn{3}{c}{ Dependent variable: } \\
\cline { 2 - 4 } & belief & click & share \\
\hline \multirow{2}{*}{ surprise } & $0.02^{* *}$ & $0.09^{* * *}$ & $0.06^{* * *}$ \\
& $(0.01)$ & $(0.01)$ & $(0.01)$ \\
true & $0.21^{* * *}$ & 0.10 & $0.14^{*}$ \\
& $(0.08)$ & $(0.07)$ & $(0.09)$ \\
surprise:true & $-0.05^{* * *}$ & -0.02 & $-0.04^{* *}$ \\
& $(0.02)$ & $(0.01)$ & $(0.02)$ \\
Constant & $0.77^{* * *}$ & $0.82^{* * *}$ & $0.68^{* * *}$ \\
& $(0.04)$ & $(0.03)$ & $(0.04)$ \\
\hline Observations & 13,410 & 13,409 & 13,409 \\
\hline \hline \multirow{2}{*}{ Note: } & $* \mathrm{p}<0.1 ;{ }^{* *} \mathrm{p}<0.05 ;{ }^{* * *} \mathrm{p}<0.01$
\end{tabular}


Table B4. Association between anger and belief, click, and share.

\begin{tabular}{lccc}
\hline \hline & \multicolumn{3}{c}{ Dependent variable: } \\
\cline { 2 - 4 } & belief & click & share \\
\hline \multirow{2}{*}{ anger } & $-0.12^{* * *}$ & $-0.10^{* * *}$ & $-0.14^{* * *}$ \\
& $(0.05)$ & $(0.04)$ & $(0.04)$ \\
true & $0.27^{* * *}$ & $0.13^{* *}$ & $0.18^{* *}$ \\
& $(0.08)$ & $(0.06)$ & $(0.07)$ \\
anger:true & 0.11 & 0.09 & 0.09 \\
& $(0.09)$ & $(0.07)$ & $(0.08)$ \\
Constant & $0.71^{* * *}$ & $0.76^{* * *}$ & $0.61^{* * *}$ \\
& $(0.04)$ & $(0.03)$ & $(0.04)$ \\
\hline Observations & 13,410 & 13,409 & 13,409 \\
\hline \hline \multirow{2}{*}{ Note: } & ${ }^{*} \mathrm{p}<0.1 ;{ }^{* *} \mathrm{p}<0.05 ;{ }^{* * *} \mathrm{p}<0.01$
\end{tabular}

Table B5. Association between fear and belief, click, and share.

\begin{tabular}{lccc}
\hline \hline & \multicolumn{3}{c}{ Dependent variable: } \\
\cline { 2 - 4 } & belief & click & share \\
\hline \multirow{2}{*}{ fear } & $0.07^{* *}$ & $0.08^{* * *}$ & $0.10^{* * *}$ \\
& $(0.03)$ & $(0.02)$ & $(0.03)$ \\
true & $0.23^{* * *}$ & $0.09^{*}$ & $0.16^{* * *}$ \\
& $(0.06)$ & $(0.05)$ & $(0.06)$ \\
fear:true & 0.02 & 0.02 & 0.08 \\
& $(0.06)$ & $(0.04)$ & $(0.07)$ \\
Constant & $0.79^{* * *}$ & $0.83^{* * *}$ & $0.70^{* * *}$ \\
& $(0.03)$ & $(0.02)$ & $(0.03)$ \\
\hline Observations & 13,410 & 13,409 & 13,409 \\
\hline \hline \multirow{2}{*}{ Note: } & $* \mathrm{p}<0.1 ;{ }^{* *} \mathrm{p}<0.05 ;{ }^{* * *} \mathrm{p}<0.01$
\end{tabular}


Table B6. Association between sad and belief, click, and share.

\begin{tabular}{lccc}
\hline \hline & \multicolumn{3}{c}{ Dependent variable: } \\
\cline { 2 - 4 } & belief & click & share \\
\hline \multirow{2}{*}{ sad } & 0.02 & 0.02 & 0.002 \\
& $(0.02)$ & $(0.03)$ & $(0.03)$ \\
true & $0.23^{* * *}$ & $0.10^{*}$ & $0.17^{* *}$ \\
& $(0.07)$ & $(0.06)$ & $(0.07)$ \\
sad:true & 0.04 & 0.06 & 0.09 \\
& $(0.05)$ & $(0.05)$ & $(0.06)$ \\
Constant & $0.77^{* * *}$ & $0.80^{* * *}$ & $0.66^{* * *}$ \\
& $(0.04)$ & $(0.03)$ & $(0.04)$ \\
\hline Observations & 13,410 & 13,409 & 13,409 \\
\hline \hline Note: & $* \mathrm{p}<0.1 ;{ }^{* *} \mathrm{p}<0.05 ;{ }^{* * *} \mathrm{p}<0.01$
\end{tabular}

Table B7. Association between disgust and belief, click, and share.

\begin{tabular}{lccc}
\hline \hline & \multicolumn{3}{c}{ Dependent variable: } \\
\cline { 2 - 4 } & belief & click & share \\
\hline \multirow{2}{*}{ disgust } & $-0.14^{* * *}$ & $-0.15^{* * *}$ & $-0.17^{* * *}$ \\
true & $(0.04)$ & $(0.03)$ & $(0.04)$ \\
& $0.25^{* * *}$ & $0.13^{* *}$ & $0.18^{* *}$ \\
disgust:true & $(0.08)$ & $(0.06)$ & $(0.08)$ \\
& 0.08 & 0.11 & 0.09 \\
Constant & $(0.08)$ & $(0.07)$ & $(0.08)$ \\
& $0.71^{* * *}$ & $0.74^{* * *}$ & $0.60^{* * *}$ \\
\hline Observations & $(0.04)$ & $(0.03)$ & $(0.04)$ \\
\hline \hline \multirow{2}{*}{ Note: } & 13,410 & 13,409 & 13,409 \\
\hline \multirow{2}{*}{${ }^{*} \mathrm{p}<0.1 ;$} & ${ }^{* *} \mathrm{p}<0.05 ;{ }^{* * *} \mathrm{p}<0.01$
\end{tabular}




\section{Appendix C: Robustness checks}

\section{C.1 Strength of emotional reaction}

For robustness, we check whether the strength of the emotional reaction similarly predicts our three outcomes for our main results for happiness and surprise. We run the same mixed-effect models replacing the emotion dummy with a variable that takes a value of 0 if the emotion was not selected, and a value between 1 and 7 as the respondent answered in the follow-up intensity question if the emotion was selected. Table C1 presents the results for happiness and Table C2 for surprise. As we can see the results remain: both happiness and surprise are associated with worse belief and sharing discernment (evidence by negative interaction terms for emotion*veracity(true)), but are both unrelated to clicking.

Table C1. Strength of emotion and outcomes: Happiness.

\begin{tabular}{lccc}
\hline \hline & \multicolumn{3}{c}{ Dependent variable: } \\
\cline { 2 - 4 } & belief & click & share \\
& $(1)$ & $(2)$ & $(3)$ \\
\hline happy strength & $0.03^{* * *}$ & $0.02^{* * *}$ & $0.03^{* * *}$ \\
& $(0.01)$ & $(0.004)$ & $(0.004)$ \\
true & $0.29^{* * *}$ & $0.12^{*}$ & $0.20^{* * *}$ \\
& $(0.08)$ & $(0.06)$ & $(0.08)$ \\
happy strength:true & $-0.03^{* * *}$ & $-0.02^{*}$ & $-0.03^{* * *}$ \\
& $(0.01)$ & $(0.01)$ & $(0.01)$ \\
Constant & $0.73^{* * *}$ & $0.77^{* * *}$ & $0.63^{* * *}$ \\
& $(0.04)$ & $(0.03)$ & $(0.04)$ \\
\hline Observations & 13,410 & 13,409 & 13,409 \\
Log Likelihood & $-5,846.00$ & $-5,392.00$ & $-6,702.00$ \\
Akaike Inf. Crit. & $11,710.00$ & $10,803.00$ & $13,422.00$ \\
Bayesian Inf. Crit. & $11,778.00$ & $10,870.00$ & $13,490.00$ \\
\hline \hline Note: & \multicolumn{2}{c}{${ }^{*} \mathrm{p}<0.1 ;{ }^{* *} \mathrm{p}<0.05 ;{ }^{* * *} \mathrm{p}<0.01$}
\end{tabular}


Table C2. Strength of emotion and outcomes: Surprise.

\begin{tabular}{lccc}
\hline \hline & \multicolumn{3}{c}{ Dependent variable: } \\
\cline { 2 - 4 } & belief & click & share \\
& $(1)$ & $(2)$ & $(3)$ \\
\hline surprise strength & $0.005^{* * *}$ & $0.02^{* * *}$ & $0.01^{* * *}$ \\
& $(0.001)$ & $(0.001)$ & $(0.001)$ \\
true & $0.24^{* * *}$ & 0.11 & $0.17^{*}$ \\
& $(0.08)$ & $(0.07)$ & $(0.09)$ \\
surprise strength:true & $-0.01^{* * *}$ & -0.004 & $-0.01^{* * *}$ \\
& $(0.003)$ & $(0.002)$ & $(0.003)$ \\
Constant & $0.76^{* * *}$ & $0.77^{* * *}$ & $0.65^{* * *}$ \\
& $(0.04)$ & $(0.03)$ & $(0.04)$ \\
\hline Observations & 13,410 & 13,409 & 13,409 \\
Log Likelihood & $-6,141.00$ & $-5,436.00$ & $-6,928.00$ \\
Akaike Inf. Crit. & $12,297.00$ & $10,886.00$ & $13,870.00$ \\
Bayesian Inf. Crit. & $12,349.00$ & $10,939.00$ & $13,923.00$ \\
\hline \hline \multirow{2}{*}{ Note: } & \multicolumn{2}{c}{${ }^{*} \mathrm{p}<0.1 ;{ }^{* *} \mathrm{p}<0.05 ;{ }^{* * *} \mathrm{p}<0.01$}
\end{tabular}

\section{C.2 Main models with controls}

Here we present linear mixed effect models looking at our three outcomes of interest for neutral (no emotion), happiness, and surprise. In each model, we control for gender, age, and education level as we prespecified in our pre-analysis plan. We also control for social media use and support for the governing party (APC), as requested by our anonymous reviewers. The tables reveal a continued positive correlation between neutral (no emotion) and belief discernment (Table C3). In fact, this relationship increases in statistical significance due to improved precision with covariate adjustment. We also observe that the negative association between happiness (Table C4) and surprise (Table C5) with both belief and sharing discernment still holds after including these controls. 
Table C3. Predicting outcomes with controls: Neutral.

\begin{tabular}{|c|c|c|c|}
\hline & \multicolumn{3}{|c|}{ Dependent variable: } \\
\hline & $\begin{array}{l}\text { belief } \\
(1)\end{array}$ & $\begin{array}{c}\text { click } \\
(2)\end{array}$ & $\begin{array}{c}\text { share } \\
(3)\end{array}$ \\
\hline neutral & $\begin{array}{c}-0.17^{* * *} \\
(0.03)\end{array}$ & $\begin{array}{c}-0.20^{* * *} \\
(0.02)\end{array}$ & $\begin{array}{c}-0.22^{* * *} \\
(0.02)\end{array}$ \\
\hline true & $\begin{array}{c}0.27^{* * *} \\
(0.09)\end{array}$ & $\begin{array}{c}0.07 \\
(0.07)\end{array}$ & $\begin{array}{c}0.15^{*} \\
(0.08)\end{array}$ \\
\hline age & $\begin{array}{l}-0.001 \\
(0.001)\end{array}$ & $\begin{array}{c}0.003^{* * *} \\
(0.001)\end{array}$ & $\begin{array}{c}0.002 \\
(0.001)\end{array}$ \\
\hline female & $\begin{array}{c}0.01 \\
(0.01)\end{array}$ & $\begin{array}{l}-0.01 \\
(0.01)\end{array}$ & $\begin{array}{c}-0.04^{* * *} \\
(0.02)\end{array}$ \\
\hline education & $\begin{array}{l}-0.002 \\
(0.005)\end{array}$ & $\begin{array}{c}-0.003 \\
(0.01)\end{array}$ & $\begin{array}{c}-0.01^{*} \\
(0.01)\end{array}$ \\
\hline social media use & $\begin{array}{l}-0.001 \\
(0.002)\end{array}$ & $\begin{array}{l}0.01^{* * *} \\
(0.003)\end{array}$ & $\begin{array}{l}0.01^{* * *} \\
(0.003)\end{array}$ \\
\hline $\mathrm{APC}$ & $\begin{array}{c}0.05^{* * *} \\
(0.02)\end{array}$ & $\begin{array}{c}0.05^{* * *} \\
(0.02)\end{array}$ & $\begin{array}{c}0.10^{* * * *} \\
(0.02)\end{array}$ \\
\hline neutral:true & $\begin{array}{l}0.13^{* *} \\
(0.06)\end{array}$ & $\begin{array}{l}-0.03 \\
(0.03)\end{array}$ & $\begin{array}{c}0.03 \\
(0.03)\end{array}$ \\
\hline Constant & $\begin{array}{c}0.74^{* * *} \\
(0.06)\end{array}$ & $\begin{array}{c}0.56^{* * *} \\
(0.06)\end{array}$ & $\begin{array}{c}0.46^{* * * *} \\
(0.08)\end{array}$ \\
\hline Observations & 13,190 & 13,190 & 13,190 \\
\hline Log Likelihood & $-5,889.00$ & $-5,223.00$ & $-6,683.00$ \\
\hline Akaike Inf. Crit. & $11,806.00$ & $10,473.00$ & $13,394.00$ \\
\hline Bayesian Inf. Crit. & $11,910.00$ & $10,578.00$ & $13,498.00$ \\
\hline
\end{tabular}


Table C4. Predicting outcomes with controls: Happiness.

\begin{tabular}{|c|c|c|c|}
\hline & \multicolumn{3}{|c|}{ Dependent variable: } \\
\hline & $\begin{array}{c}\text { belief } \\
(1)\end{array}$ & $\begin{array}{l}\text { click } \\
(2)\end{array}$ & $\begin{array}{c}\text { share } \\
(3)\end{array}$ \\
\hline happy & $\begin{array}{c}0.15^{* * *} \\
(0.03)\end{array}$ & $\begin{array}{c}0.11^{* * *} \\
(0.03)\end{array}$ & $\begin{array}{c}0.16^{* * *} \\
(0.03)\end{array}$ \\
\hline true & $\begin{array}{c}0.19^{* * *} \\
(0.06)\end{array}$ & $\begin{array}{c}0.08 \\
(0.05)\end{array}$ & $\begin{array}{c}0.11^{*} \\
(0.06)\end{array}$ \\
\hline age & $\begin{array}{l}-0.001 \\
(0.001)\end{array}$ & $\begin{array}{c}0.003^{* * * *} \\
(0.001)\end{array}$ & $\begin{array}{c}0.002^{*} \\
(0.001)\end{array}$ \\
\hline female & $\begin{array}{c}0.004 \\
(0.01)\end{array}$ & $\begin{array}{l}-0.02 \\
(0.01)\end{array}$ & $\begin{array}{c}-0.05^{* * *} \\
(0.02)\end{array}$ \\
\hline education & $\begin{array}{l}-0.002 \\
(0.005)\end{array}$ & $\begin{array}{c}-0.003 \\
(0.01)\end{array}$ & $\begin{array}{c}-0.01^{*} \\
(0.01)\end{array}$ \\
\hline social media use & $\begin{array}{c}-0.0000 \\
(0.002)\end{array}$ & $\begin{array}{l}0.01^{* * *} \\
(0.003)\end{array}$ & $\begin{array}{l}0.01^{* * *} \\
(0.004)\end{array}$ \\
\hline $\mathrm{APC}$ & $\begin{array}{c}0.05^{* * *} \\
(0.02)\end{array}$ & $\begin{array}{c}0.06^{* * *} \\
(0.02)\end{array}$ & $\begin{array}{c}0.10^{* * *} \\
(0.02)\end{array}$ \\
\hline happy:true & $\begin{array}{c}-0.20^{* * *} \\
(0.06)\end{array}$ & $\begin{array}{c}-0.09^{*} \\
(0.05)\end{array}$ & $\begin{array}{c}-0.20^{* * *} \\
(0.05)\end{array}$ \\
\hline Constant & $\begin{array}{c}0.83^{* * * *} \\
(0.05) \\
\end{array}$ & $\begin{array}{c}0.64^{* * * *} \\
(0.06)\end{array}$ & $\begin{array}{c}0.57^{* * *} \\
(0.07)\end{array}$ \\
\hline Observations & 13,190 & 13,190 & 13,190 \\
\hline Log Likelihood & $-5,751.00$ & $-5,276.00$ & $-6,599.00$ \\
\hline Akaike Inf. Crit. & $11,529.00$ & $10,581.00$ & $13,226.00$ \\
\hline Bayesian Inf. Crit. & $11,634.00$ & $10,685.00$ & $13,331.00$ \\
\hline
\end{tabular}


Table C5. Predicting outcomes with controls: Surprise.

\begin{tabular}{|c|c|c|c|}
\hline & \multicolumn{3}{|c|}{ Dependent variable: } \\
\hline & $\begin{array}{c}\text { belief } \\
(1) \\
\end{array}$ & $\begin{array}{c}\text { click } \\
(2) \\
\end{array}$ & $\begin{array}{c}\text { share } \\
(3)\end{array}$ \\
\hline surprise & $\begin{array}{l}0.02^{* *} \\
(0.01)\end{array}$ & $\begin{array}{c}0.09^{* * * *} \\
(0.01)\end{array}$ & $\begin{array}{c}0.06^{* * * *} \\
(0.01)\end{array}$ \\
\hline true & $\begin{array}{c}0.22^{* * * *} \\
(0.08)\end{array}$ & $\begin{array}{c}0.10 \\
(0.07)\end{array}$ & $\begin{array}{c}0.15^{*} \\
(0.09)\end{array}$ \\
\hline age & $\begin{array}{l}-0.001 \\
(0.001)\end{array}$ & $\begin{array}{c}0.003^{* * *} \\
(0.001)\end{array}$ & $\begin{array}{c}0.002^{*} \\
(0.001)\end{array}$ \\
\hline female & $\begin{array}{c}0.004 \\
(0.01)\end{array}$ & $\begin{array}{l}-0.01 \\
(0.01)\end{array}$ & $\begin{array}{c}-0.05^{* * *} \\
(0.02)\end{array}$ \\
\hline education & $\begin{array}{l}-0.002 \\
(0.005)\end{array}$ & $\begin{array}{c}-0.003 \\
(0.01)\end{array}$ & $\begin{array}{c}-0.01^{*} \\
(0.01)\end{array}$ \\
\hline social media use & $\begin{array}{l}0.0002 \\
(0.002)\end{array}$ & $\begin{array}{l}0.01^{* * * *} \\
(0.003)\end{array}$ & $\begin{array}{l}0.01^{* * *} \\
(0.004)\end{array}$ \\
\hline $\mathrm{APC}$ & $\begin{array}{c}0.05^{* * *} \\
(0.02)\end{array}$ & $\begin{array}{c}0.06^{* * * *} \\
(0.02)\end{array}$ & $\begin{array}{c}0.10^{* * *} \\
(0.02)\end{array}$ \\
\hline surprise:true & $\begin{array}{c}-0.06^{* * *} \\
(0.02)\end{array}$ & $\begin{array}{c}-0.02^{*} \\
(0.01)\end{array}$ & $\begin{array}{c}-0.04^{* *} \\
(0.02)\end{array}$ \\
\hline Constant & $\begin{array}{c}0.79^{* * * *} \\
(0.06)\end{array}$ & $\begin{array}{c}0.64^{* * *} \\
(0.06)\end{array}$ & $\begin{array}{c}0.54^{* * * *} \\
(0.08)\end{array}$ \\
\hline Observations & 13,190 & 13,190 & 13,190 \\
\hline Log Likelihood & $-6,039.00$ & $-5,321.00$ & $-6,821.00$ \\
\hline Akaike Inf. Crit. & $12,103.00$ & $10,665.00$ & $13,666.00$ \\
\hline Bayesian Inf. Crit. & $12,192.00$ & $10,755.00$ & $13,756.00$ \\
\hline
\end{tabular}

\section{C.3 Examining partisanship}

Table C6 interacts support for the governing party ("APC") with our main independent variables of interest: headline veracity and an indicator for the absence of any emotional reaction (neutral). We see that the triple interaction term is not statistically significant, but the main interaction of interest (neutral*true) does not change in magnitude. In other words, the relationship between emotional reaction, veracity, and belief in the headline does not differ by partisanship. This is also the case when we include the triple interaction in our regressions for happiness (Table C7). For surprise (Table C8), our main result for belief (surprise*true) remains similar in magnitude as well. Here we also see that the triple interaction term is statistically significant, which means there is a difference between APC supporters' and other respondents' belief in true/false headlines when they are surprised by the headline. More broadly, we also see that APC supporters are more likely to believe, click, and share headlines than nonpartisans and opposition supporters. These results suggest that partisanship is significantly related to belief in headlines-APC supporters are less likely to believe true headlines than other respondents-but partisanship does not alter the relationship between emotions and our outcomes of interest. The relationship between partisanship and reactions to misinformation should be further studied in this context. 
Table C6. Interacting support for governing party with emotional reaction and headline veracity.

\begin{tabular}{lccc}
\hline \hline & \multicolumn{3}{c}{ Dependent variable: } \\
\cline { 2 - 4 } & belief & click & share \\
\hline neutral & $-0.17^{* * *}$ & $-0.21^{* * *}$ & $-0.23^{* * *}$ \\
true & $(0.03)$ & $(0.02)$ & $(0.02)$ \\
& $0.27^{* * *}$ & 0.07 & $0.15^{*}$ \\
APC & $(0.09)$ & $(0.07)$ & $(0.08)$ \\
& 0.03 & $0.10^{* * *}$ & $0.17^{* * *}$ \\
neutral:true & $(0.03)$ & $(0.03)$ & $(0.03)$ \\
& $0.10^{*}$ & -0.04 & 0.02 \\
neutral:APC & $(0.06)$ & $(0.04)$ & $(0.04)$ \\
true:APC & -0.03 & $0.08^{*}$ & $0.13^{* *}$ \\
& $(0.05)$ & $(0.05)$ & $(0.05)$ \\
neutral:true:APC & -0.01 & 0.06 & 0.02 \\
& $(0.04)$ & $(0.04)$ & $(0.04)$ \\
Constant & 0.10 & 0.12 & 0.07 \\
& $(0.08)$ & $(0.08)$ & $(0.09)$ \\
\hline Observations & $0.70^{* * *}$ & $0.71^{* * *}$ & $0.57^{* * *}$ \\
\hline \hline Note: & $(0.05)$ & $(0.03)$ & $(0.04)$ \\
\hline & 13,410 & 13,409 & 13,409 \\
\hline \multirow{2}{*}{ * } & ${ }^{*} \mathrm{p}<0.1 ;{ }^{* *} \mathrm{p}<0.05 ;{ }^{* * *} \mathrm{p}<0.01$ \\
& & &
\end{tabular}


Table C7. Interacting support for governing party with happy and headline veracity.

\begin{tabular}{lccc}
\hline \hline & \multicolumn{3}{c}{ Dependent variable: } \\
\cline { 2 - 4 } & belief & click & share \\
\hline \multirow{2}{*}{ happy } & $0.16^{* * *}$ & $0.12^{* * *}$ & $0.17^{* * *}$ \\
& $(0.03)$ & $(0.03)$ & $(0.03)$ \\
true & $0.20^{* * *}$ & 0.08 & $0.11^{*}$ \\
& $(0.06)$ & $(0.05)$ & $(0.06)$ \\
APC & $0.05^{* *}$ & $0.05^{* * *}$ & $0.11^{* * *}$ \\
& $(0.02)$ & $(0.02)$ & $(0.03)$ \\
happy:true & $-0.20^{* * *}$ & $-0.08^{*}$ & $-0.19^{* * *}$ \\
& $(0.06)$ & $(0.05)$ & $(0.05)$ \\
happy:APC & -0.01 & $-0.08^{* * *}$ & $-0.07^{* * *}$ \\
& $(0.03)$ & $(0.02)$ & $(0.03)$ \\
true:APC & $-0.05^{* *}$ & -0.01 & -0.02 \\
& $(0.02)$ & $(0.02)$ & $(0.03)$ \\
happy:true:APC & 0.04 & -0.04 & -0.01 \\
& $(0.05)$ & $(0.05)$ & $(0.05)$ \\
Constant & $0.80^{* * *}$ & $0.82^{* * *}$ & $0.69^{* * *}$ \\
& $(0.03)$ & $(0.03)$ & $(0.03)$ \\
\hline Observations & 13,410 & 13,409 & 13,409 \\
\hline \hline Note: & ${ }^{*} \mathrm{p}<0.1 ;{ }^{* *} \mathrm{p}<0.05 ;{ }^{* * *} \mathrm{p}<0.01$
\end{tabular}

Table C8. Interacting support for governing party with surprise and headline veracity.

\begin{tabular}{lccc}
\hline \hline & \multicolumn{3}{c}{ Dependent variable: } \\
\cline { 2 - 4 } & belief & click & share \\
\hline surprise & 0.01 & $0.09^{* * *}$ & $0.05^{* *}$ \\
& $(0.01)$ & $(0.03)$ & $(0.02)$ \\
true & $0.22^{* * *}$ & 0.08 & $0.13^{*}$ \\
& $(0.07)$ & $(0.06)$ & $(0.08)$ \\
APC & $0.05^{* * *}$ & $0.06^{* * *}$ & $0.12^{* * *}$ \\
& $(0.02)$ & $(0.02)$ & $(0.02)$ \\
surprise:true & $-0.04^{*}$ & -0.04 & -0.05 \\
& $(0.03)$ & $(0.05)$ & $(0.04)$ \\
surprise:APC & 0.04 & $-0.04^{*}$ & 0.005 \\
& $(0.02)$ & $(0.02)$ & $(0.03)$ \\
true:APC & $-0.07^{* * *}$ & 0.004 & -0.02 \\
& $(0.02)$ & $(0.02)$ & $(0.02)$ \\
surprise:true:APC & $-0.11^{* *}$ & -0.001 & -0.05 \\
& $(0.05)$ & $(0.04)$ & $(0.05)$ \\
Constant & $0.76^{* * *}$ & $0.81^{* * *}$ & $0.66^{* * *}$ \\
& $(0.04)$ & $(0.03)$ & $(0.04)$ \\
\hline Observations & 13,410 & 13,409 & 13,409 \\
\hline \hline Note: & $* \mathrm{p}<0.1 ; * * \mathrm{p}<0.05 ;{ }^{* * *} \mathrm{p}<0.01$
\end{tabular}


Table C9 analyzes the correlation between support for the governing party (APC) and trust in different media sources. Respondents who report supporting the governing party (APC) trust what they see on television and hear on the radio more than other respondents - who either support a different party or do not identify with any political party. Interestingly, however, there is not a statistically significant (at the conventional $5 \%$ ) difference in trust levels between APC partisans and other respondents with respect to social media.

Table C9. Correlation between support for governing party and trust in different media.

\begin{tabular}{|c|c|c|c|}
\hline & \multicolumn{3}{|c|}{ Dependent variable: } \\
\hline & T.V. & Radio & Social Media \\
\hline $\mathrm{APC}$ & $\begin{array}{c}0.25^{* * * *} \\
(0.08)\end{array}$ & $\begin{array}{c}0.19^{* *} \\
(0.09)\end{array}$ & $\begin{array}{c}0.16^{*} \\
(0.09)\end{array}$ \\
\hline Constant & $\begin{array}{c}1.10^{* * * *} \\
(0.03)\end{array}$ & $\begin{array}{c}0.99^{* * *} \\
(0.03)\end{array}$ & $\begin{array}{c}0.37^{* * * *} \\
(0.03)\end{array}$ \\
\hline Observations & 1,289 & 1,224 & 1,301 \\
\hline $\mathrm{R}^{2}$ & 0.01 & 0.004 & 0.002 \\
\hline Adjusted $\mathrm{R}^{2}$ & 0.01 & 0.003 & 0.002 \\
\hline
\end{tabular}

\section{C.4 Leave one out analysis}

The graphs below plot the coefficients on the interaction terms (emotion*veracity) for the linear mixed effect models predicting belief. These graphs plot estimates on the $y$ axis. The points represent the iterated estimates when 1 out of the 10 headlines is removed from the analysis (to ensure that the results are not being driven by any particular headline). The $x$-axis indicates which headline is left out. We see that the results are not driven by a particular headline. 


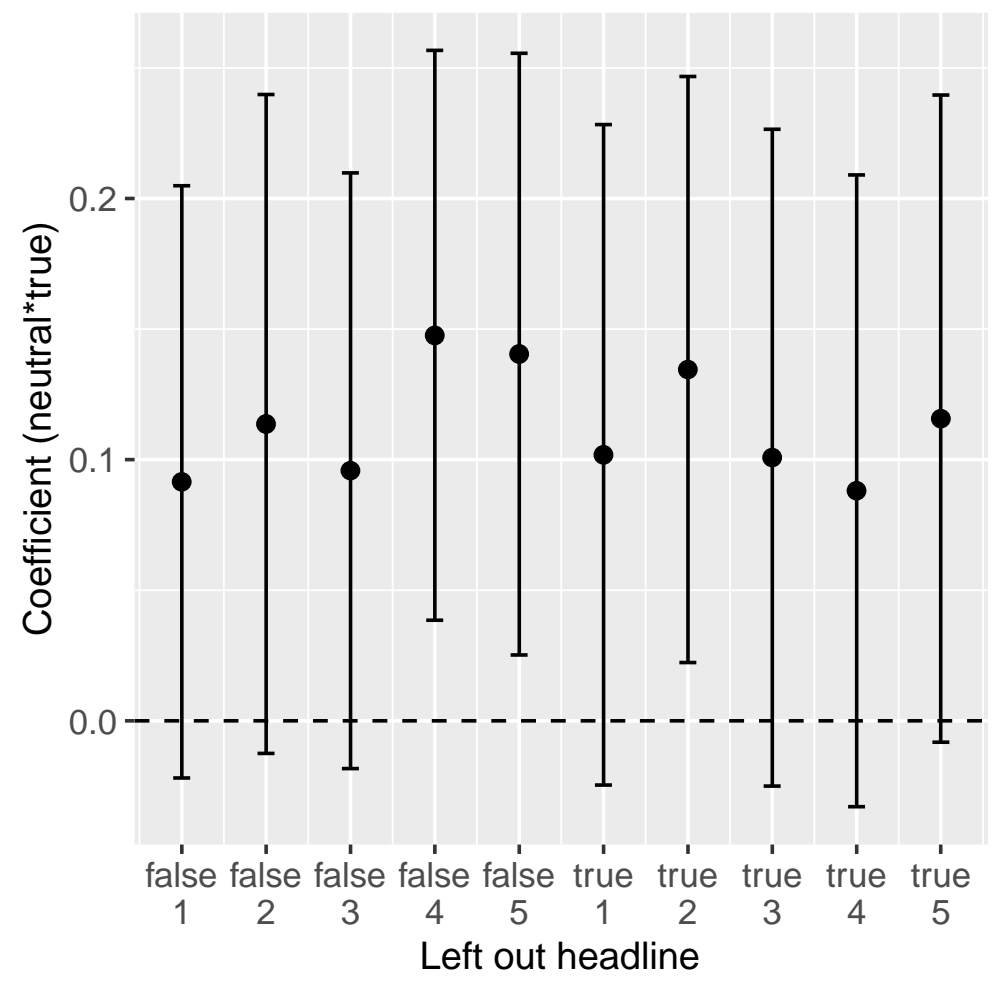

Figure C1. Leave one out analysis - Neutral.

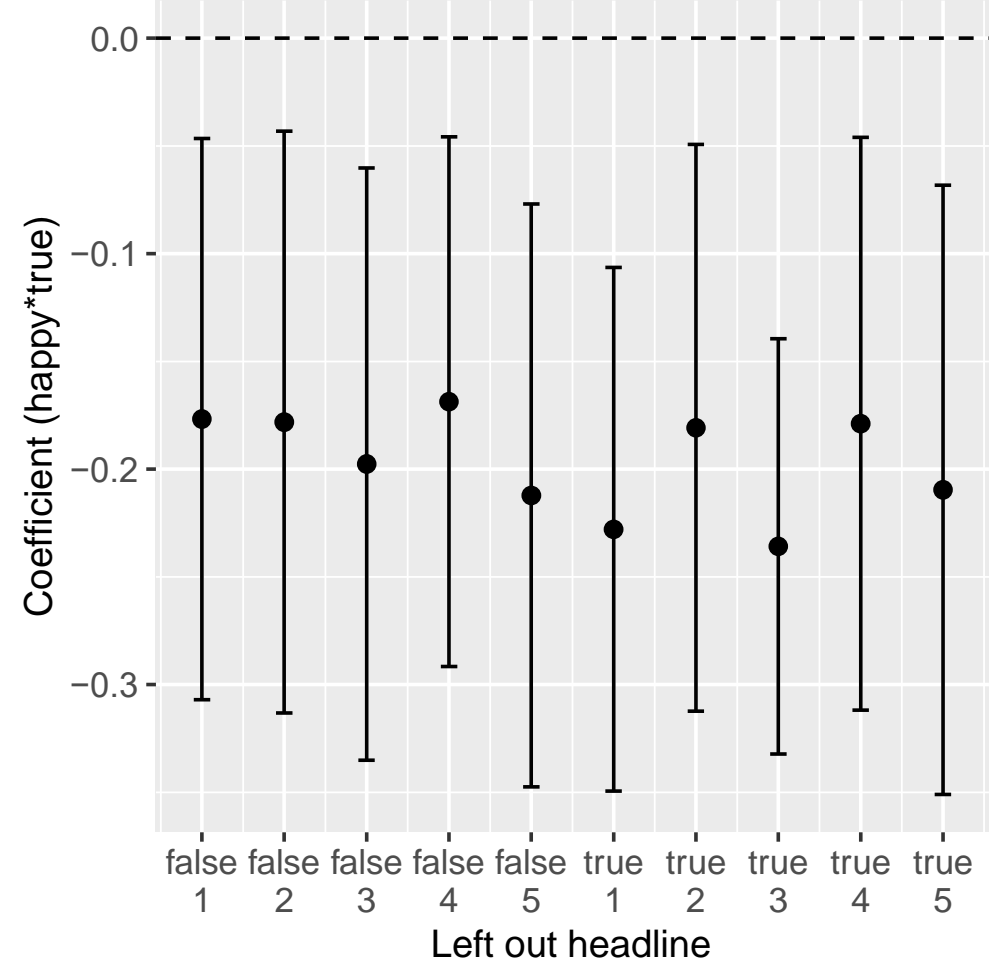

Figure C2. Leave one out analysis - Happiness. 


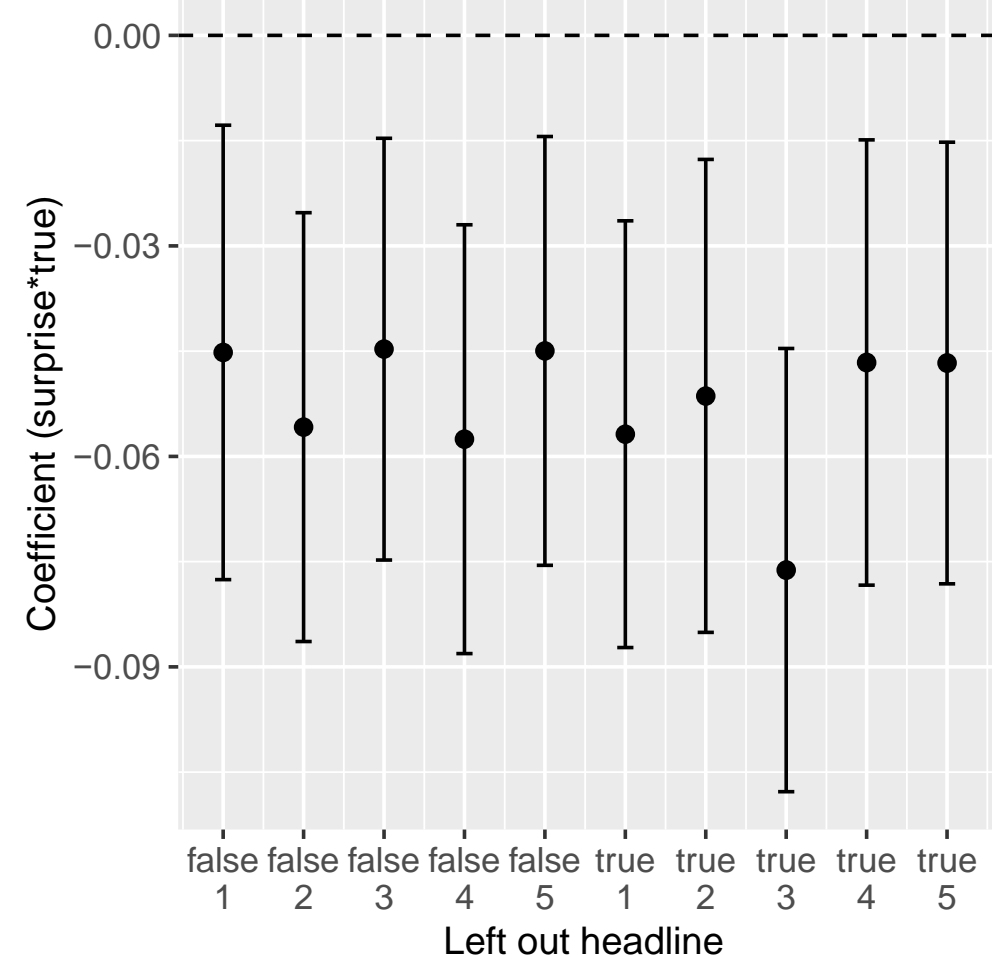

Figure C3. Leave one out analysis - Surprise.

\section{C.5 Order of questions}

Does being asked about emotions/belief first matter? We check and verify in Table C10 that the order of the questions (emotions and then belief, or belief and then emotions) is not correlated with our outcomes at the conventional $5 \%$ level nor is it differentially correlated with discernment for these outcomes. 
Table C10. Order of questions for each outcome.

\begin{tabular}{|c|c|c|c|}
\hline & \multicolumn{3}{|c|}{ Dependent variable: } \\
\hline & $\begin{array}{l}\text { belief } \\
(1)\end{array}$ & $\begin{array}{c}\text { click } \\
(2)\end{array}$ & $\begin{array}{c}\text { share } \\
(3)\end{array}$ \\
\hline True & $\begin{array}{c}2.00^{* * * *} \\
(0.57)\end{array}$ & $\begin{array}{l}1.00^{* *} \\
(0.49)\end{array}$ & $\begin{array}{l}1.10^{* *} \\
(0.55)\end{array}$ \\
\hline Emotion first & $\begin{array}{l}0.17^{*} \\
(0.09)\end{array}$ & $\begin{array}{c}0.07 \\
(0.11)\end{array}$ & $\begin{array}{c}0.17 \\
(0.12)\end{array}$ \\
\hline True:Emotion first & $\begin{array}{c}0.08 \\
(0.10)\end{array}$ & $\begin{array}{c}-0.17^{*} \\
(0.10)\end{array}$ & $\begin{array}{c}0.04 \\
(0.09)\end{array}$ \\
\hline Constant & $\begin{array}{l}0.77^{*} \\
(0.40)\end{array}$ & $\begin{array}{c}1.60^{* * * *} \\
(0.35)\end{array}$ & $\begin{array}{c}0.59 \\
(0.40)\end{array}$ \\
\hline Observations & 13,410 & 13,409 & 13,409 \\
\hline Log Likelihood & $-5,874.00$ & $-5,564.00$ & $-6,606.00$ \\
\hline Akaike Inf. Crit. & $11,761.00$ & $11,140.00$ & $13,223.00$ \\
\hline Bayesian Inf. Crit. & $11,806.00$ & $11,185.00$ & $13,269.00$ \\
\hline
\end{tabular}




\section{Appendix D: Stimuli}

\section{D.1 Stimuli descriptives}

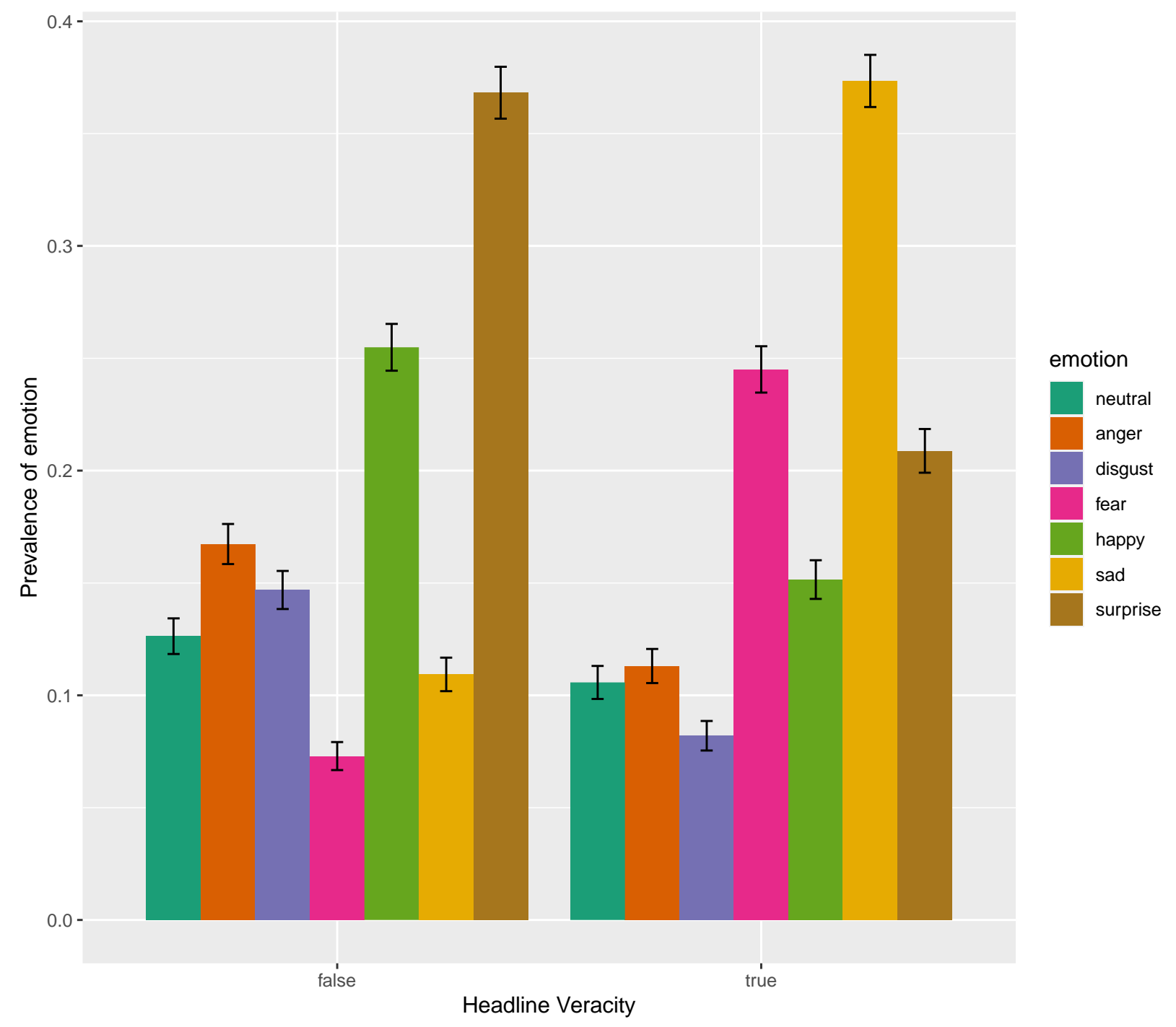

Figure D1. Prevalence of emotions by veracity. 
Table D1. Distribution of emotions for each stimulus.

\begin{tabular}{lrrrrrrrrrr}
\hline Headline & False 1 & False 2 & False 3 & False 4 & False 5 & True 1 & True 2 & True 3 & True 4 & True 5 \\
\hline fear mean & 0.03 & 0.15 & 0.04 & 0.05 & 0.09 & 0.21 & 0.03 & 0.39 & 0.13 & 0.46 \\
fear sd & 0.18 & 0.35 & 0.21 & 0.21 & 0.29 & 0.41 & 0.18 & 0.49 & 0.34 & 0.50 \\
anger mean & 0.04 & 0.34 & 0.05 & 0.19 & 0.21 & 0.04 & 0.28 & 0.05 & 0.06 & 0.13 \\
anger sd & 0.20 & 0.47 & 0.22 & 0.39 & 0.41 & 0.19 & 0.45 & 0.21 & 0.25 & 0.34 \\
sad mean & 0.05 & 0.20 & 0.04 & 0.10 & 0.16 & 0.53 & 0.13 & 0.46 & 0.23 & 0.51 \\
sad sd & 0.21 & 0.40 & 0.20 & 0.30 & 0.36 & 0.50 & 0.34 & 0.50 & 0.42 & 0.50 \\
happy mean & 0.51 & 0.04 & 0.50 & 0.14 & 0.09 & 0.03 & 0.06 & 0.14 & 0.49 & 0.04 \\
happy sd & 0.50 & 0.19 & 0.50 & 0.35 & 0.28 & 0.17 & 0.24 & 0.35 & 0.50 & 0.19 \\
surprise mean & 0.43 & 0.29 & 0.42 & 0.42 & 0.28 & 0.32 & 0.33 & 0.12 & 0.11 & 0.17 \\
surprise sd & 0.50 & 0.45 & 0.49 & 0.49 & 0.45 & 0.47 & 0.47 & 0.32 & 0.31 & 0.38 \\
disgust mean & 0.04 & 0.21 & 0.05 & 0.17 & 0.27 & 0.03 & 0.28 & 0.03 & 0.03 & 0.05 \\
disgust sd & 0.20 & 0.41 & 0.21 & 0.37 & 0.44 & 0.17 & 0.45 & 0.16 & 0.17 & 0.22 \\
neutral mean & 0.11 & 0.11 & 0.11 & 0.14 & 0.16 & 0.10 & 0.14 & 0.10 & 0.14 & 0.05 \\
neutral sd & 0.31 & 0.31 & 0.31 & 0.35 & 0.36 & 0.30 & 0.35 & 0.30 & 0.34 & 0.21 \\
belief mean & 0.66 & 0.55 & 0.68 & 0.67 & 0.72 & 0.94 & 0.59 & 0.96 & 0.94 & 0.96 \\
belief sd & 0.47 & 0.50 & 0.47 & 0.47 & 0.45 & 0.23 & 0.49 & 0.20 & 0.25 & 0.20 \\
click mean & 0.84 & 0.73 & 0.83 & 0.72 & 0.65 & 0.86 & 0.63 & 0.92 & 0.87 & 0.94 \\
click sd & 0.36 & 0.44 & 0.38 & 0.45 & 0.48 & 0.35 & 0.48 & 0.28 & 0.34 & 0.24 \\
share mean & 0.71 & 0.51 & 0.68 & 0.55 & 0.53 & 0.71 & 0.46 & 0.86 & 0.79 & 0.87 \\
share sd & 0.45 & 0.50 & 0.47 & 0.50 & 0.50 & 0.45 & 0.50 & 0.35 & 0.40 & 0.34 \\
\hline
\end{tabular}

Table D2. Distributions of outcomes for each stimulus.

\begin{tabular}{lrrrrrrrrrr}
\hline Headline & False 1 & False 2 & False 3 & False 4 & False 5 & True 1 & True 2 & True 3 & True 4 & True 5 \\
\hline belief mean & 0.66 & 0.55 & 0.68 & 0.67 & 0.72 & 0.94 & 0.59 & 0.96 & 0.94 & 0.96 \\
belief sd & 0.47 & 0.50 & 0.47 & 0.47 & 0.45 & 0.23 & 0.49 & 0.20 & 0.25 & 0.20 \\
click mean & 0.84 & 0.73 & 0.83 & 0.72 & 0.65 & 0.86 & 0.63 & 0.92 & 0.87 & 0.94 \\
click sd & 0.36 & 0.44 & 0.38 & 0.45 & 0.48 & 0.35 & 0.48 & 0.28 & 0.34 & 0.24 \\
share mean & 0.71 & 0.51 & 0.68 & 0.55 & 0.53 & 0.71 & 0.46 & 0.86 & 0.79 & 0.87 \\
share sd & 0.45 & 0.50 & 0.47 & 0.50 & 0.50 & 0.45 & 0.50 & 0.35 & 0.40 & 0.34 \\
\hline
\end{tabular}




\section{D.2 Stimuli images}

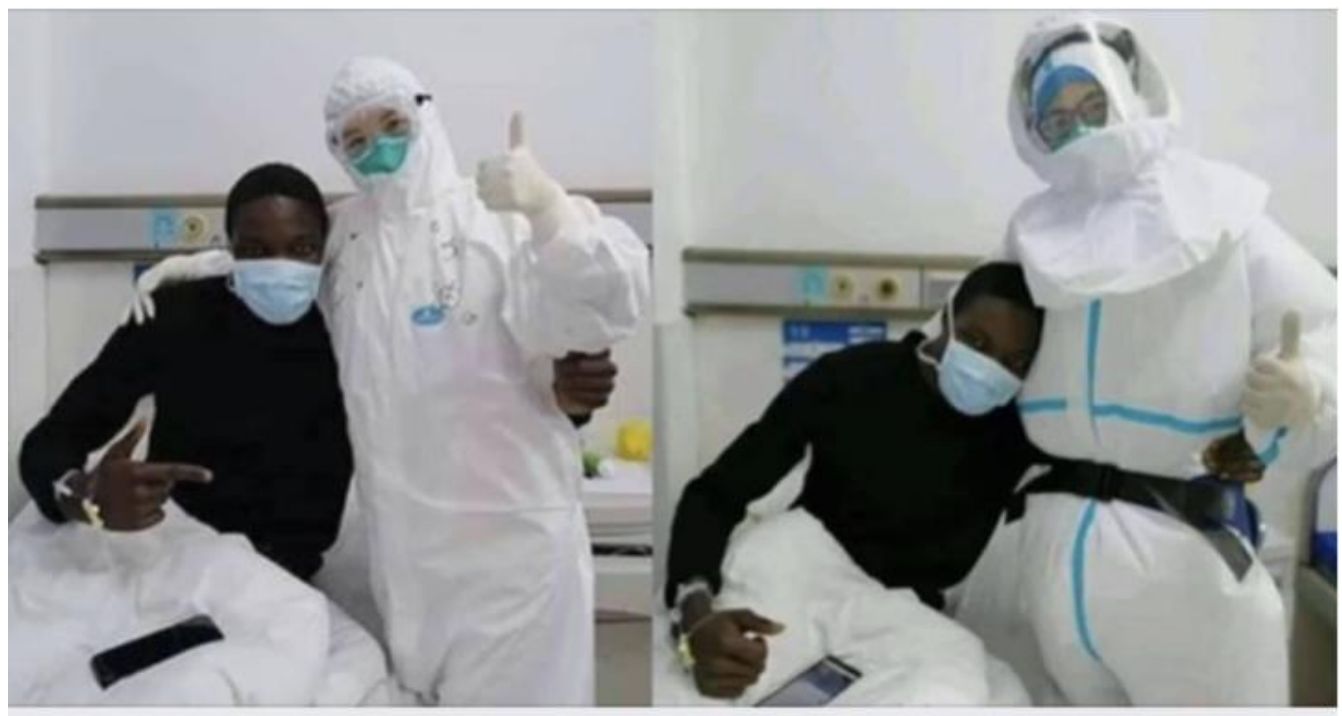

CITYSCROLLZ.COM

Chinese Doctors Confirmed African Blood Genetic Composition Resist Coronavirus After Student Cured

Figure D2. False 1.

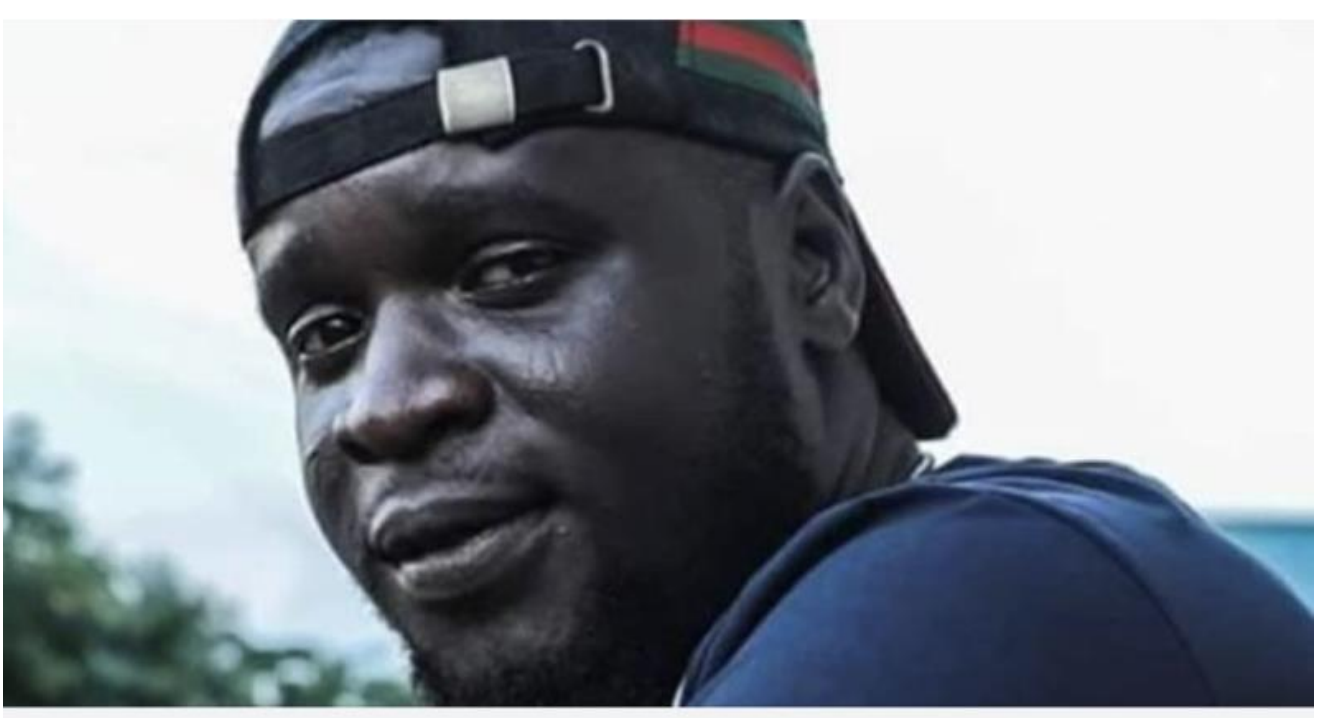

NAIJALIVETV.COM

JUST IN: Man who Drove the Italian Man to Ogun Diagnosed with Coronavirus, Escaped, Demand for N100Million,...

Figure D3. False 2. 


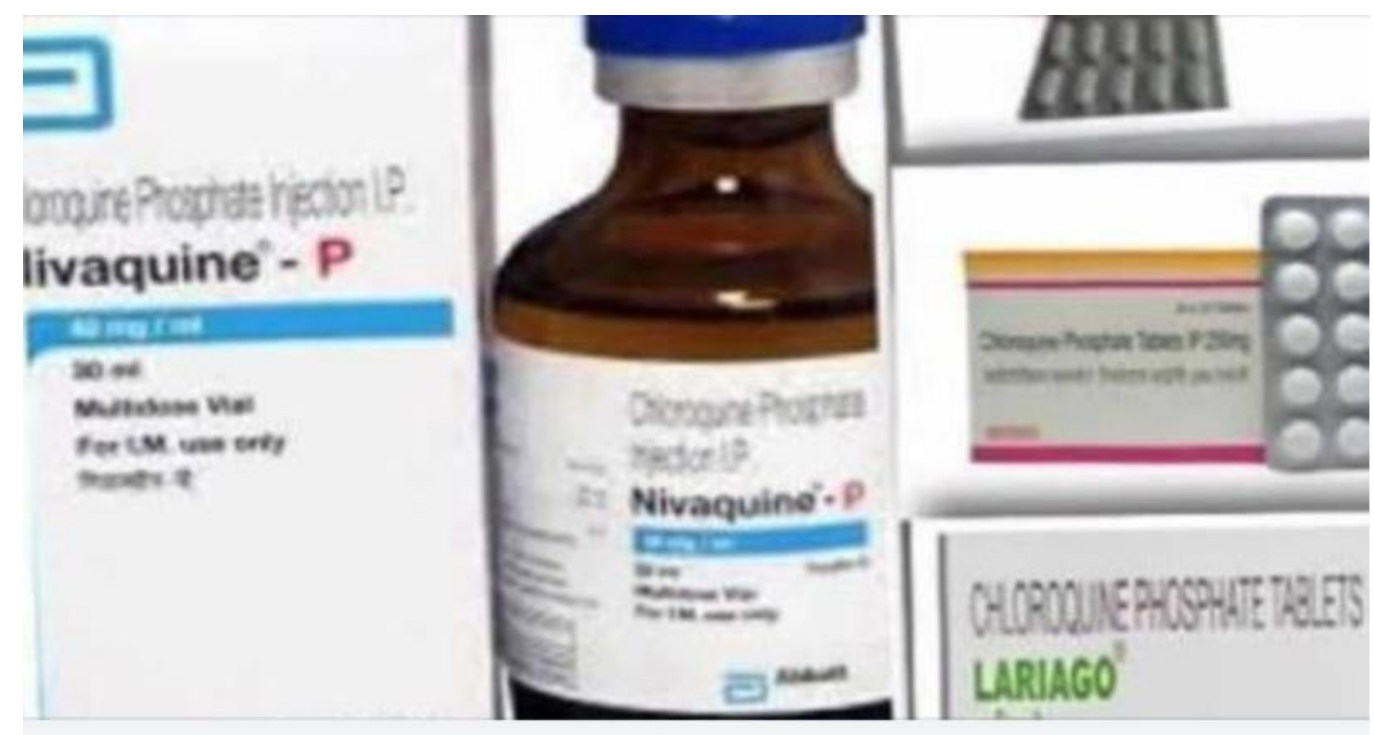

TRIBUNEONLINENG.COM

Chloroquine found effective against coronavirus, cures 12,552 patients in China

Figure D4. False 3.

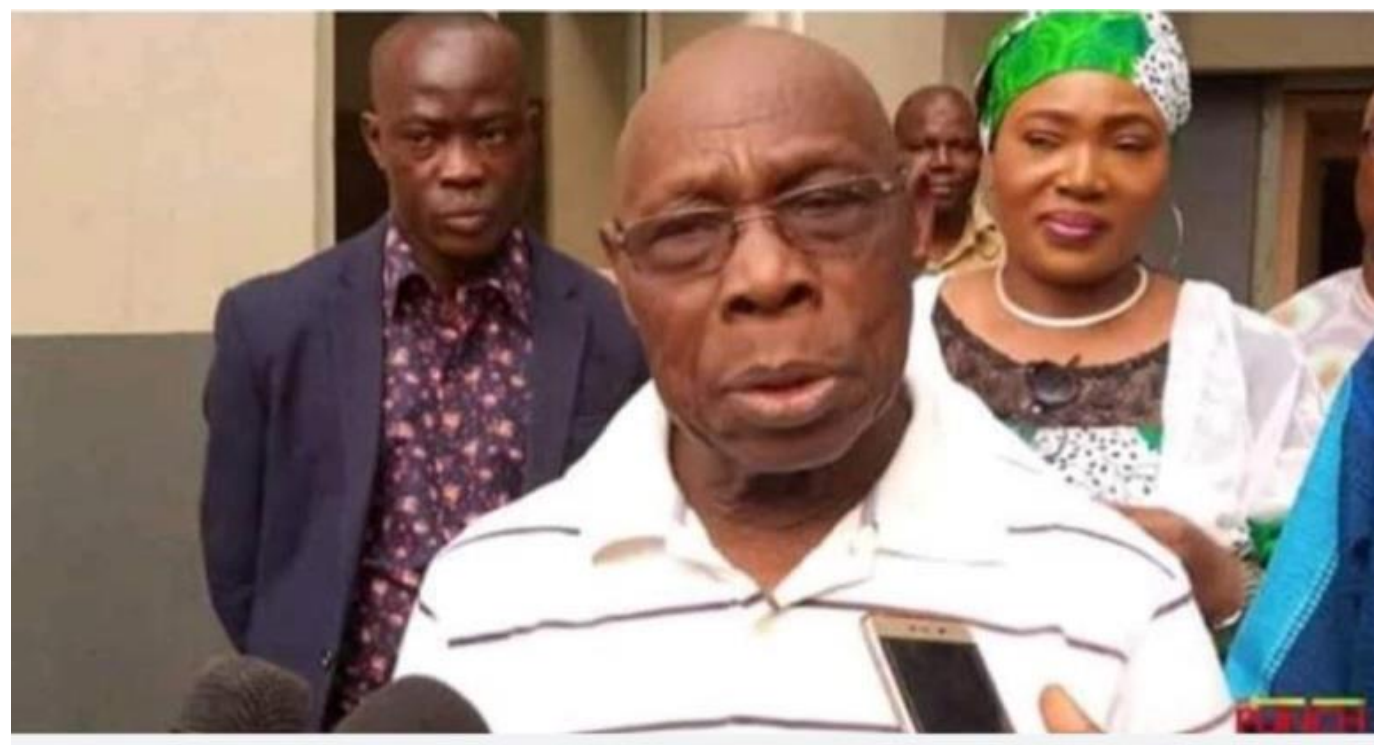

FOXNEWSNIGERIA.COM

"There is no coronavirus in Nigeria...I want to see the Italian man, I wan get the virus too" says Obasanjo

Figure D5. False 4. 


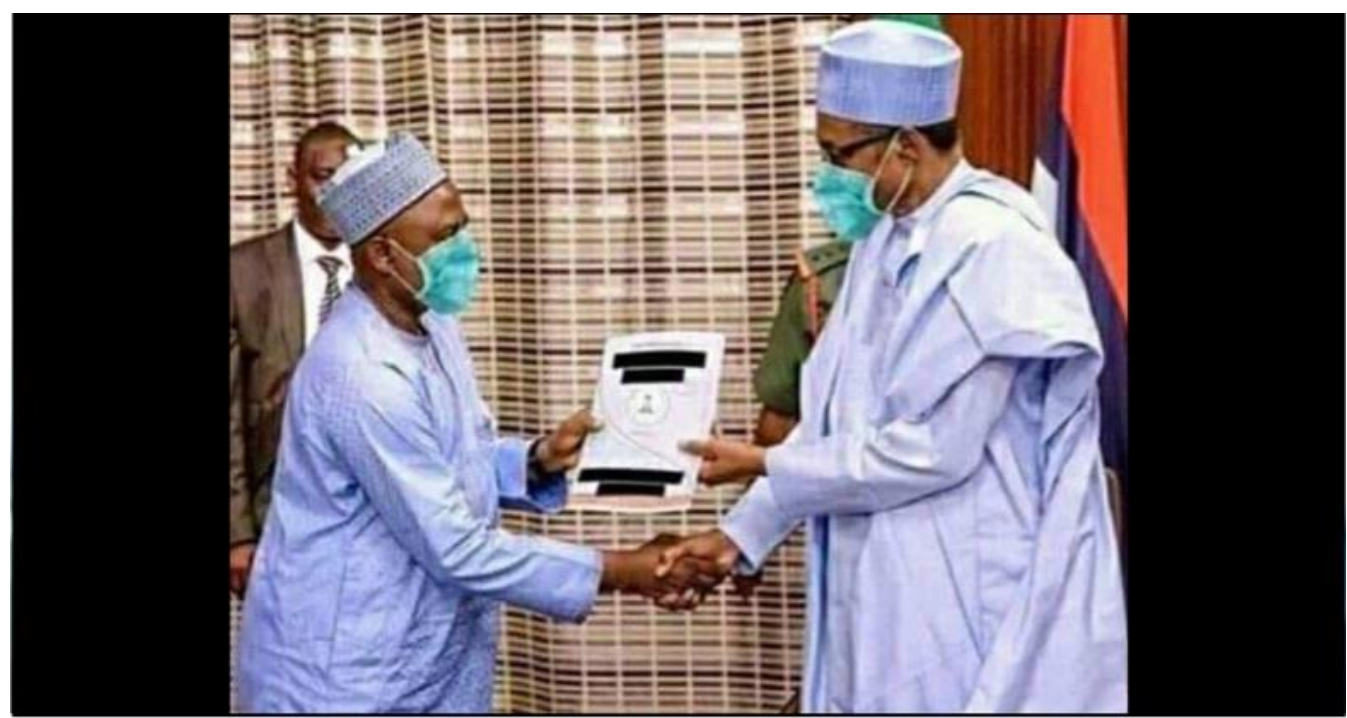

SCANNEWSNIGERIA.COM

President Muhammadu Buhari covering a face mask and having a skin to skin HANDSHAKE.

Figure D6. False 5.

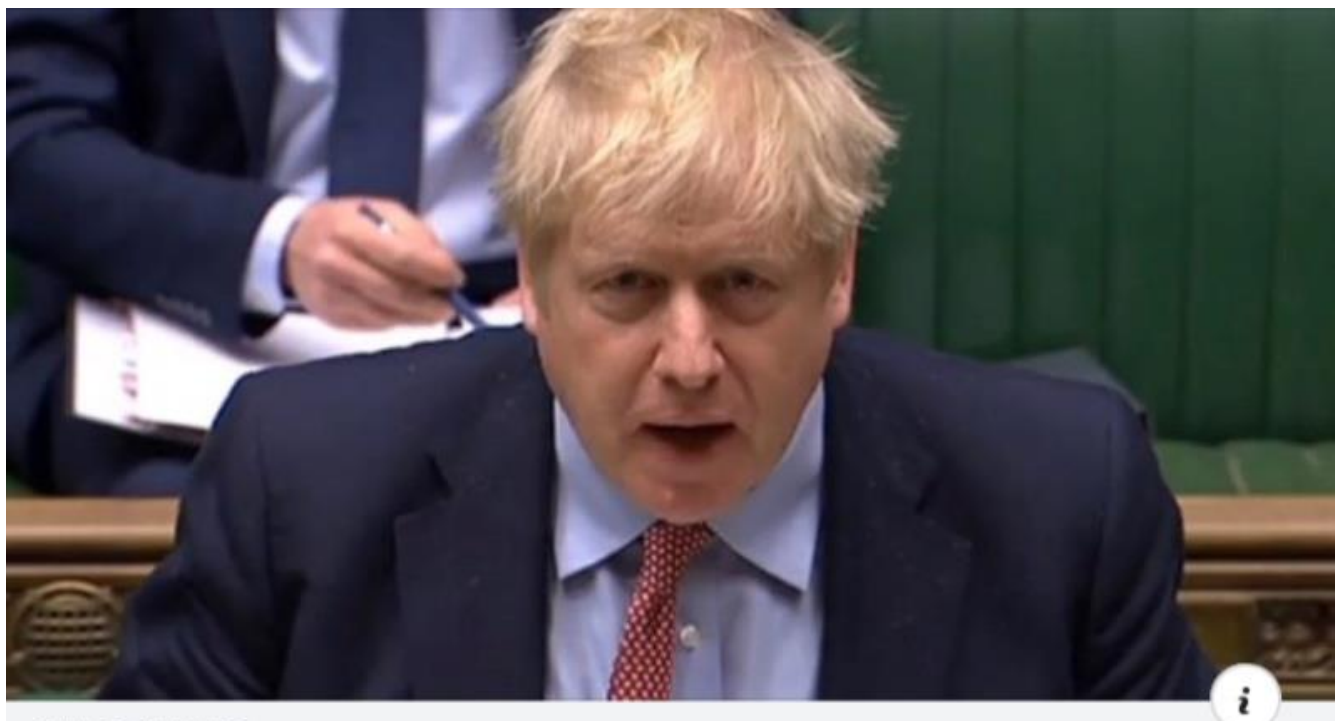

GUARDIAN.NG

British Prime Minister Boris Johnson tests positive for coronavirus

Figure D7. True 1. 


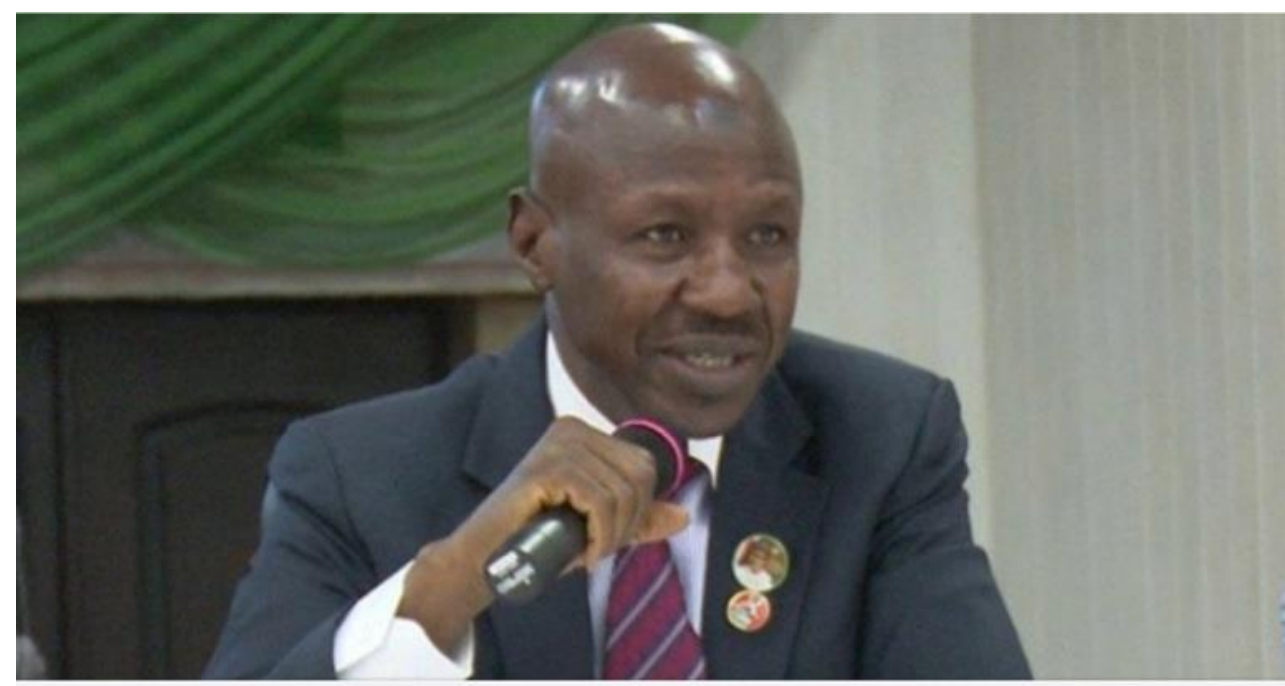

URBANLIFEPOST.COM

Coronavirus caused by corruption says EFCC boss, Magu

Mr. Magu The acting Chairman of Economic and Financial Crimes Commissio...

Figure D8. True 2.

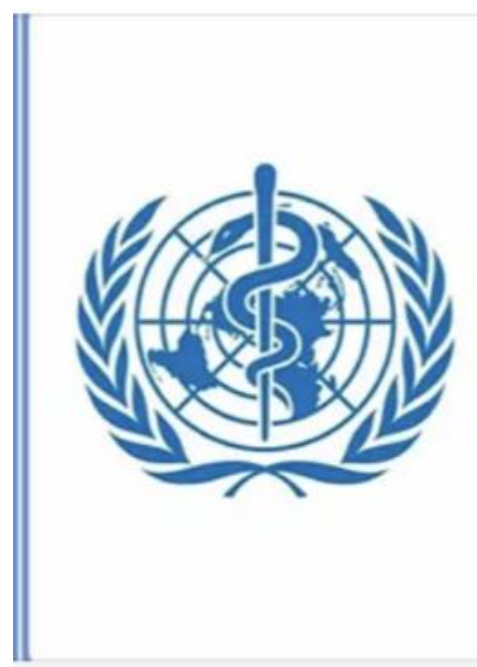

\section{World Health Organization}

DAILYPOST.NG

WHO declares coronavirus global health emergency - Daily Post Nigeria

Figure D9. True 3. 


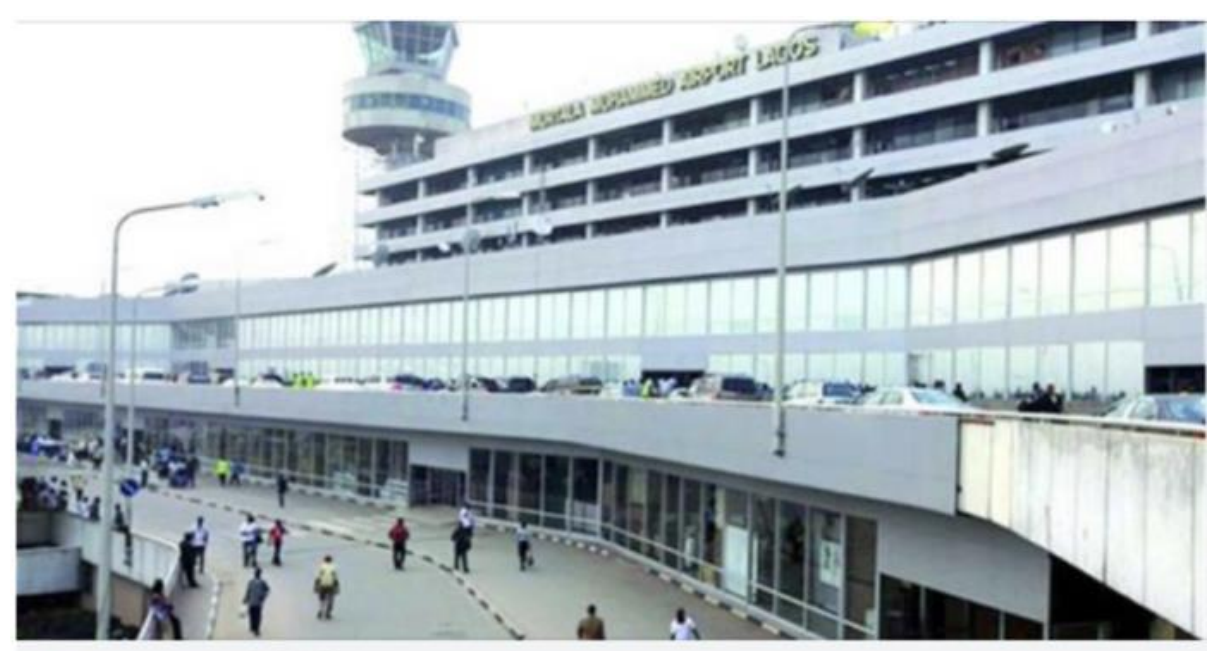

PREMIUMTIMESNG.COM

UPDATED: Nigeria bans all international flights as coronavirus cases rise

Figure D10. True 4.

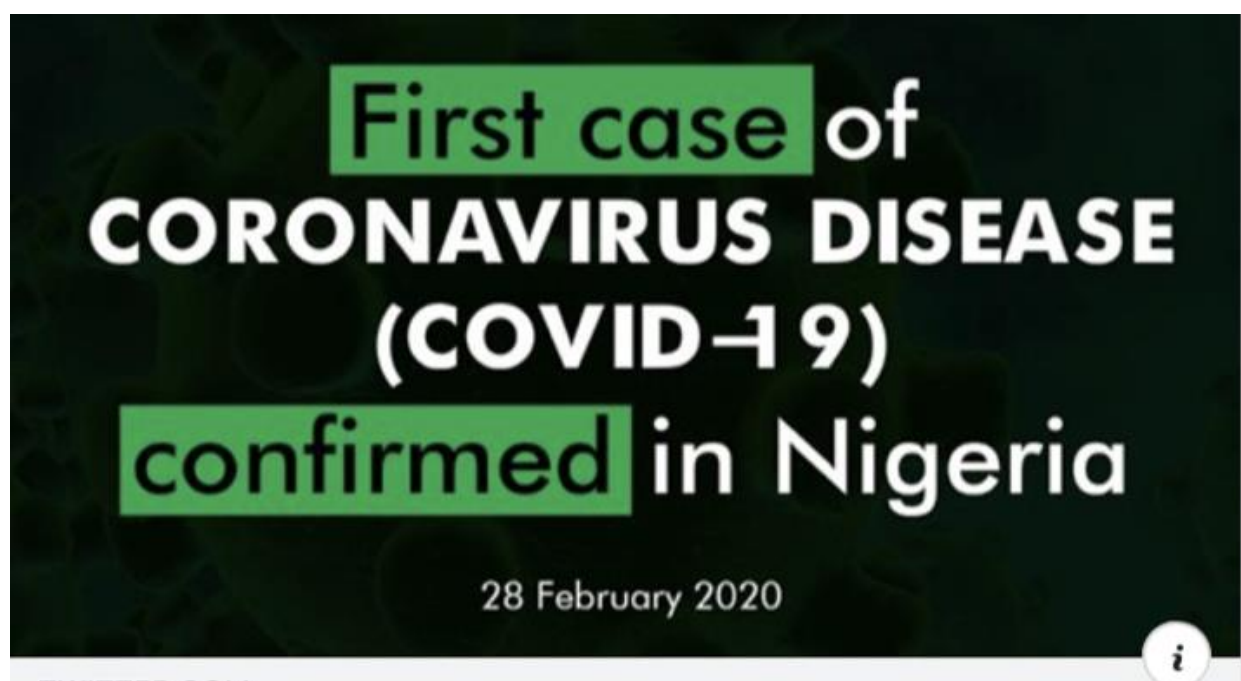

TWITTER.COM

Federal Ministry of Health, NIGERIA on Twitter

"The Federal Ministry of Health has confirmed a coronavirus(Covid-1...

Figure D11. True 5. 